Research Paper

\title{
Mutation Hot Spots in Spike Protein of SARS-CoV-2 Virus
}

\author{
FEROZA BEGUM ${ }^{1,2}$, ARUP KUMAR BANERJEE ${ }^{3, *}$ and UPASANA RAY ${ }^{1,2,{ }^{*}}$ \\ ${ }^{1}$ Infectious Biology and Immunology Division, CSIR-Indian Institute of Chemical Biology, 4, Raja S.C., \\ Mullick Road, Jadavpur, Kolkata 700 032, West Bengal, India \\ ${ }^{2}$ Academy of Scientific and Innovative Research (AcSIR), Ghaziabad 201 002, India \\ ${ }^{3}$ Department of Biochemistry, North Bengal Medical College and Hospital, Sushrutanagar, Siliguri 734 \\ 012, West Bengal, India
}

(Received on 10 June 2020; Revised on 04 September 2020; Accepted on 10 September 2020)

\begin{abstract}
Spike (S) protein of Corona viruses help in receptor attachment and virus entry into the host cells. While $\mathrm{S}$ protein is required for virus entry, it is also important as an immunogen as it is the most accessible part of the virus architecture. $\mathrm{S}$ protein form knob like structures (viral spikes) protruding outwards in the form of homotrimers containing an S1 and S2 as monomers. Mutations in structural proteins of virus play crucial role in determining virulence and also in many instances influencing emergence of antibody escape variants and cellular tropism. In this paper we have performed in depth analyses of spike protein sequences from various parts of the world and tried to correlate the data with possible functional relevance of such mutations.
\end{abstract}

Keywords: COVID-19; SARS-CoV-2; S Protein; RBD; S1; S2

\section{Introduction}

In recent times novel coronavirus 2019/ nCoV-19/ COVID 19/ SARS CoV2 infection has become a pandemic and matter of concern worldwide. As per the World Health Organization (https://www.who.int/ emergencies/diseases/novel-coronavirus-2019/ situation-reports/), globally, there have been millions of confirmed COVID 19 cases millions have died.

The global sequencing effort have led to significant numbers of SARS-CoV-2 sequence information available now in various sequence databases specifically dedicated for COVID-19 research. Although number of sequences are increasing, the representation of various countries varies notably with more representations from few and very little from many others. Thus, this is a limiting factor in the field of sequence-based studies.

Spike protein is one of the most important structural proteins of SARS-CoV-2 that plays the major role in virus attachment to its receptor followed by cellular entry (Tai et al., 2020; Lon et al., 2020; Hoffnan et al., 2020). It is one of the major structural proteins, 1273aa long, with two major sub domains, S1 and S2 (Fig. 1). While S1 harbours the receptor binding domain or RBD and mediates virus attachment to its ACE2 receptor, S2 carries out the function of fusion to enable successful entry.

Viruses evolve by continuously mutating its gene sequences and the frequency of mutation is also attributed to the lack of proof-reading activity of the viral replication machinery. In case of SARS-CoV-2, the virus had proof-reading properties. Yet, mutations appear albeit at a slowly. The correlation between mutations and function/s of viral protein/s becomes important while designing drug/vaccine candidates.

Here, we have studied the profile of mutations occurring in the spike protein world-wide and also laid more in-depth analyses of the sequences available from Indian patients.

*Author for Correspondence: E-mail: ray.upasana@gmail.com; upasana.ray@iicb.res.in; drarup.banerjee@gmail.com 
A

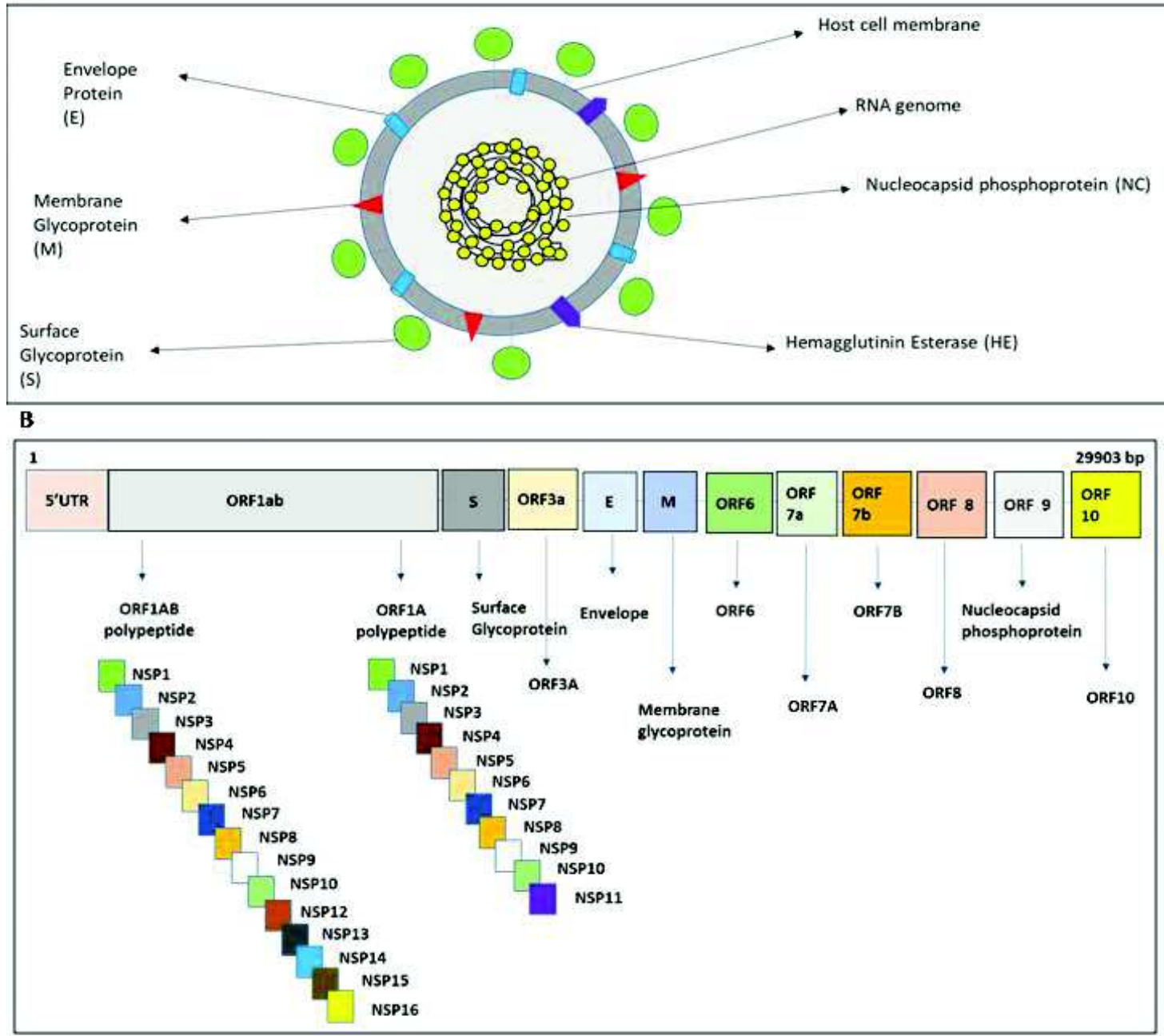

C

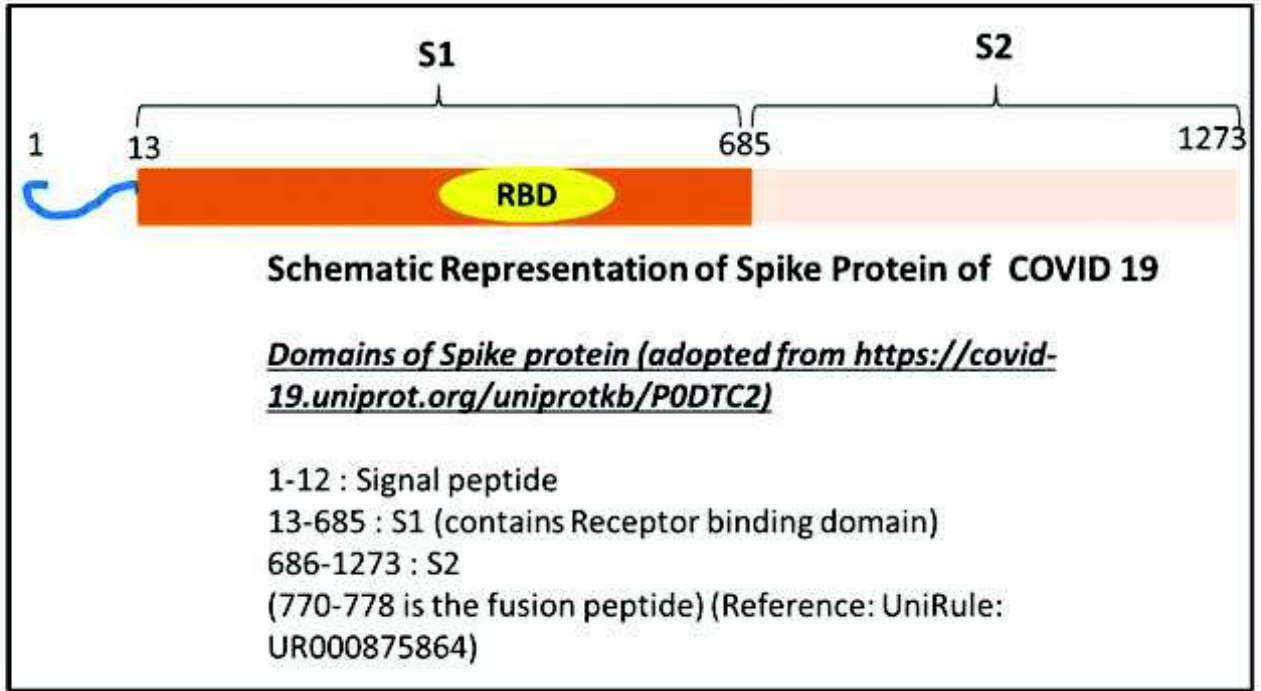

Fig. 1: SARS-CoV-2 viral proteins. A. Schematic Representation of SARS-CoV2 virus; B. Schematic Representation of SARSCoV-2 genome and different proteins encoded (NCBI Ref ID NC_045512.2); C. Schematic showing structural organization of COVID 19 spike protein. Spike protein is 1273aa long with two main domains, S1 and S2. 13-685aa form the $S 1$ domain and rest of the S protein comprises the S2 domain. The receptor binding domain (RBD) falls within $S 1$ domain 


\section{Methods}

\section{Sequence Information}

A total of 11,571 available full length annotated sequences of SARS-CoV-2 spike protein (1-1273) of different geographical origins belonging to Asia (1017 sequences), Africa (103 sequences), Europe (441 sequences), Oceania (1426 sequences) (Australia: 1423 sequences and Guam 3 sequences), North America (8564 sequences) and South America (20 sequences) were downloaded from NCBI virus database for sequence analyses.

Additionally, 1648 whole genome sequences of SARS-CoV-2 deposited from Indian patients were also downloaded from GISAID database for detailed spike protein mutation analysis in Indian context. Although around 2000 sequences from Indian origin have been deposited in the GISAID database, not all are well sequenced with respect to the protein sequence of interest. Thus, only 1648 sequences with good translatable sequence information were used for current sequence analyses.

Accession YP_009724390.1 was used as the reference sequence.

\section{Sequence Analyses}

Multiple Sequence Alignment (MSA) was done using Clustal Omega and MAFFT V7 tools. Surface glycoprotein coding regions from GISAID database were translated using ExPaSy protein translation tool (https://web.expasy.org/translate/). The translated sequences were further aligned using Clustal Omega tool (https://www.ebi.ac.uk/Tools/msa/clustalo/).

\section{Prediction of Protein Stability Change}

Since D614G is one of the most dominant mutation, the effect of this mutation on spike protein stability and flexibility was studied using DynaMut prediction that uses Normal Mode Analysis (NMA). The SARSCoV-2 spike ectodomain structure (open state) (PDB ID: 6VYB) was downloaded from RCSB PDB, uploaded on DynaMut software (University of Melbourne, Australia) and changes in vibrational entropy; the atomic fluctuations and deformation energies were determined for mutation D614G. For atomic fluctuation and deformation energy calculations, calculations were performed by the software over first ten non-trivial modes of the molecule.

\section{Visualization of Sites of RBD Mutation with Respect to ACE Receptor Interaction Face}

To visualise the mutated amino acid positions in SARSCoV2 Spike RBD region with respect to ACE receptor the crystal structure of spike RBD with ACE2 was downloaded from PDB (PDB ID: 6LZG). The structure was viewed using PyMoL software and the two proteins were differently coloured along with the amino acids that were found to have mutated.

\section{Results and Discussion}

Multiple sequence alignment of COVID-19 spike protein sequences from various geographical locations world-wide revealed the types of mutations occurring since the outbreak as the pandemic progressed. Although, there were many mutations dispersed at various sites in the spike protein sequence, few mutations occurred more frequently (Fig. 2A) i.e. in multiple isolates/sequences.

\section{Spike Protein Mutations World-wide}

Till date there are several thousands of SARS-CoV2 sequencing data available for analyses on different databases. To understand the mutation profile of spike protein on world-wide level representing multiple continents or geographical sources, we used all the available annotated full-length sequences of the spike protein from all the major continents from NCBI virus database. 11,571 sequences in total were taken into consideration as shown in Table 1.

While there were commonly occurring random mutations, as many as 15 mutations were detected to be occurring in a country specific manner and represented to be present indifferent domains of the SARS-CoV-2 spike protein. Out of 15 mutations detected, 8 of them lie in S1 domain, 6 of them lie in $\mathrm{S} 2$ domain and 1 of them lie in signal peptide. The signal peptide residue mutation, L5F is seen mainly in the USA sequences. Mutation in the signal peptide might modulate in the signalling events in the intracellular secretory pathway although the exact relevance can only be ascertained by cell culturebased assays on virus-host interactions. In the S1 domain, 8 mutations were detected in different continents out of which 4 were detected in Asia. India 
Table 1: Mutational analysis of Spike protein of SARS-CoV2 isolated from different continents. Mutations in the S1 domain (residues 13-685) and S2 domain (686-1273) are highlighted in red and blue respectively. Mutations lying in the Receptor binding domain (RBD) is highlighted in green and are also part of the S1 subunit

\begin{tabular}{|c|c|c|c|}
\hline $\begin{array}{l}\text { Continents (Total } \\
\text { number of sequences } \\
\text { analysed) }\end{array}$ & $\begin{array}{l}\text { Counties (Number of sequences } \\
\text { used) }\end{array}$ & $\begin{array}{l}\text { Specific/Exclusive mutations observed } \\
\text { in different country specific spike protein } \\
\text { sequences (Reference sequence: } \\
\text { YP_009724390.1) }\end{array}$ & $\begin{array}{l}\text { Percentage of sequences } \\
\text { showing the mutation }\end{array}$ \\
\hline \multirow[t]{18}{*}{ Asia (1017) } & 1. Bahrain (10) & & \\
\hline & 2. Bangladesh (171) & & \\
\hline & 3. China (121) & & \\
\hline & 4. Georgia (9) & & \\
\hline & 5. India (455) & $\begin{array}{l}\text { A) L54F(372L, 83F) } \\
\text { B) R78M }(442 \mathrm{R}, 13 \mathrm{M})\end{array}$ & $\begin{array}{l}18.2 \% \\
2.9 \%\end{array}$ \\
\hline & & C) E583D (441E,14D) & $3.1 \%$ \\
\hline & 6. Iran (6) & A) T22I $(3 \mathrm{~T}, 3 \mathrm{I})$ & $50 \%$ \\
\hline & 7. Japan (68) & B) G1219V (64G,4V) & $5.9 \%$ \\
\hline & 8. Kazakhstan (4) & & \\
\hline & 9. Malaysia(4) & & \\
\hline & 10. Pakistan (3) & & \\
\hline & 11. Saudi Arabia (58) & & \\
\hline & 12. South Korea (6) & & \\
\hline & 13. Sri Lanka (4) & & \\
\hline & 14. Taiwan (31) & A) T791I (24T,7I) & $22.6 \%$ \\
\hline & 15. Thailand (63) & A) $\mathrm{A} 829 \mathrm{~T}(25 \mathrm{~A}, 38 \mathrm{~T})$ & $60.3 \%$ \\
\hline & 16. Vietnam (2) & & \\
\hline & 17. Israel (2) & & \\
\hline \multirow[t]{4}{*}{ Africa (103) } & 1. Egypt (83) & A) $\mathrm{Q} 677 \mathrm{H}(74 \mathrm{Q}, 8 \mathrm{H}, 1 \mathrm{X})$ & $9.6 \%$ \\
\hline & 2. Morocco (10) & & \\
\hline & 3. Tunisia (8) & & \\
\hline & 4. Kenya (2) & & \\
\hline \multirow[t]{10}{*}{ Europe (441) } & 1. Czech Republic (23) & & \\
\hline & 2. France $(85)$ & A) A845S $(78 \mathrm{~A}, 7 \mathrm{~S})$ & $8.2 \%$ \\
\hline & 3. Germany (79) & & \\
\hline & 4. Greece (98) & & \\
\hline & 5. Italy (14) & & \\
\hline & 6. Poland (31) & & \\
\hline & 7. Russia (8) & & \\
\hline & 8. Serbia (11) & & \\
\hline & 9. Spain (37) & & \\
\hline & 10. Turkey (55) & A) M900I (31M,23I,1X) & $41.8 \%$ \\
\hline \multirow[t]{4}{*}{ Oceania (1426) } & 1. Australia (1423) & A) S477N(1084S,59N,280X) & $4.1 \%$ \\
\hline & & B) G485R(1086G,31R,306X) & $2.2 \%$ \\
\hline & & C) N501Y (1096N,14Y,313X) & $1.0 \%$ \\
\hline & 2. Guam (3) & & \\
\hline \multirow[t]{3}{*}{ North America (8564) } & 1. USA (8544) & A) L5F (8434L,97F,13X) & $1.1 \%$ \\
\hline & 2. Puerto Rico (12) & B) P1263L (8476P,59L,9X) & $0.7 \%$ \\
\hline & 3. Jamaica (8) & & \\
\hline \multirow[t]{3}{*}{ South America (20) } & 1. Brazil (6) & & \\
\hline & 2. Chile (11) & & \\
\hline & 3. Colombia (3) & & \\
\hline
\end{tabular}


alone represented three of these mutations of the in the S1 domain namely L54F, R78M and E583D (Table 1). Further analysis of other Asian isolates revealed mutations at other positions, namely T22I (Iran), G1219V (Japan), T791I (Taiwan) and A829T (Thailand). Although more sequence analyses alter current judgements made, the emergence of mutations signify the evolving nature of the spike protein albeit at various levels. Three of the mutations S477N, G485R and N501Y lying in the receptor binding domain (RBD) might alter the virus-ACE2 receptor interactions or could potentially lead to involvement of other receptors or co-receptors. Alteration of receptor interactions does not necessarily indicate effect on virulence and the hypothesis by itself requires time-testing i.e., monitoring positive selection of the emerging mutations and also wet lab validations.

S2 domain helps in the fusion process. In S2 domain, 6 mutations were detected out of which 3 were detected in Asian isolates. The S2 mutations were more prevalent as compared to $\mathrm{S} 1$ especially T791I which occurred in $22.6 \%$ of sequence analysed from Taiwan and A829T which neared $60.3 \%$ in those from Thailand. Other 3 mutations were detected in France (A845S), Turkey (M900I) and USA (P1263L). These mutations have a frequency of $8.2 \%, 41.8 \%$ and $0.7 \%$ respectively.

Overall, there were 18 major mutations noted and each one emerged at different time points on the pandemic time scale (Table 2, Fig. 2A). D614G and A829T mutations were the first major mutations to emerge as early as in the month of January albeit only in few places during that time point. Table 2 enlists the accession numbers of the sequences where each of the major mutations primarily appeared. M900I appear to be one of the recent ones with the sample collection date being in July.

\section{Mutation 614G}

Mutation at 614 from Aspartic acid to glycine is one of the mutations that appeared in more than $70 \%$ of the sequences in all the continents except in Oceania (major geographical location is Australia) where it appeared in $66.8 \%$ of the sequences (Table 3, Fig. 7). Mutation from Aspartic acid to glycine is a potentially crucial change in a protein sequence as Aspartic acid is a big negatively charged, acidic amino acid whereas Glycine is a small neutral amino acid and thus a change from $\mathrm{D}$ to $\mathrm{G}$ might lead to electrostatic alterations. In a study by Feng et al. [7], it was shown that when there was a mutation from $G$ to $\mathrm{D}$ in the RNA dependent RNA polymerase PB1 of H5N1 virus, the binding of PB1 to viral RNA was hampered and $\mathrm{H} 5 \mathrm{~N} 1$ was attenuated. In case of COVID 19 spike protein since, residue 614 is positioned between $\mathrm{S} 1$ and S2 and a D to G change might affect the binding of spike with its receptor. In this study we used in silico platform of DynaMut prediction (which uses Normal Mode Analysis/NMA) to check the effect of D614G mutation on the structural stability, flexibility, atomic fluctuations (amplitude of absolute atomic motions) and deformation energies (change in local flexibilities) (Fig. 8). This mutation was seen to stabilize the structure and decrease molecular flexibility. Since Aspartic acid to Glycine is a major electrostatic change, this might also lead to formation of an antibody escape mutant if position 614 is a part of immunogenic epitope. In case this position is a part of an epitope, this mutation might help the virus to escape the immune system and proliferate into a new more adapted cluster. Currently, D614G mutation has been a topic of debate and functional relevance of this mutation with respect to virulence has not been established. This assumption can be validated by incorporating this mutation in a laboratory isolate followed by testing cellular tropism and affinity for neutralizing antibodies.

\section{Mutation at Receptor Binding Domain}

Tables 4-6 and Fig. 3 show a compilation of all the $\mathrm{RBD}$ related mutations. We have shown this analysis separately as the receptor binding domain has been the focus of drug targeting and vaccine development because of the role in receptor binding. We observed that RBD has seen three major mutations showing percentage varying from $1 \%-4 \%$ of the total sequences of each geographical location. All these mutations were from Oceania (Table 4). In one of our previous studies published as a pre-print we had analysed mainly North American sequences as the study was performed at an earlier stage of the current pandemic and the availability of sequence was a limitation. In case of North America, we previously noted three mutations in the RBD domain, A348T, G476S and V483A. However, the frequency of mutations these are currently $<1 \%$, hence these mutations are not propagating further or propagating 
Table 2: Major mutations detected in SARS-CoV2 Spike protein and its probable period of primary appearance (based on the collection date of the sample). The NCBI accession ID has been mentioned for the sequence where the mutation was detected

\begin{tabular}{|c|c|c|}
\hline Mutations & $\begin{array}{l}\text { Date of it first occurrence } \\
\text { in the year } 2020 \text { (day- } \\
\text { month-year) }\end{array}$ & $\begin{array}{l}\text { Accession ID of } \\
\text { the sequence where } \\
\text { the mutation was } \\
\text { detected (NCBI) }\end{array}$ \\
\hline 1. D614G & 00-01-2020 & QJW69187.1 \\
\hline 2. A829T & $23-01-2020$ & QJQ84712.1 \\
\hline 3. G485R & 06-02-2020 & QJG65949.1 \\
\hline 4. T791I & $26-02-2020$ & QJD20632.1 \\
\hline 5. V483A & $29-02-2020$ & QKS90227.1 \\
\hline 6. A845S & $00-03-2020$ & QJT72086.1 \\
\hline 7. G476S & 02-03-2020 & QKS90479.1 \\
\hline 8. L5F & 09-03-2020 & QIZ15981.1 \\
\hline 9. P1263L & $14-03-2020$ & QLC92372.1 \\
\hline 10. S477N & $19-03-2020$ & QLG76889.1 \\
\hline 11. T22I & $26-03-2020$ & QKV67308.1 \\
\hline 12. R78M & $11-04-2020$ & QJY40517.1 \\
\hline 13. E583D & $11-04-2020$ & QJY40565.1 \\
\hline 14. G1219V & $00-05-2020$ & BCI50555.1 \\
\hline 15. L54F & 04-05-2020 & QJX44562.1 \\
\hline 16. Q677H & 02-06-2020 & QKX65100.1 \\
\hline 17. N501Y & 03-06-2020 & QLG75761.1 \\
\hline 18. M900I & $15-07-2020$ & QLK97783.1 \\
\hline
\end{tabular}

Table 3: Mutational analysis of $614^{\text {th }}$ a.a. of SARS-CoV2 Spike protein

\begin{tabular}{lll}
\hline Continents & Countries (Total number & Percentage of \\
(Total number & of sequences used) & sequences \\
of sequences & & showing D/G \\
used) & & at the $614^{\text {th }}$ \\
& position
\end{tabular}

Asia (1017)

$\begin{array}{ll}\text { 1. Bahrain (10) } & \text { 9G,1D } \\ \text { 2. Bangladesh (171) } & \text { 168G,3D } \\ \text { 3. China (121) } & \text { 3G, 118D } \\ \text { 4. Georgia (9) } & 6 \mathrm{G}, 3 \mathrm{D} \\ \text { 5. India (455) } & \text { 414G,41D } \\ \text { 6. Iran (6) } & 6 \mathrm{D} \\ \text { 7. Japan (68) } & \text { 59G,9D }\end{array}$

\begin{tabular}{|c|c|c|}
\hline & 8. Kazakhstan (4) & $2 \mathrm{G}, 2 \mathrm{D}$ \\
\hline & 9. Malaysia (4) & $4 \mathrm{D}$ \\
\hline & 10. Pakistan (3) & $3 \mathrm{D}$ \\
\hline & 11. Saudi Arabia (58) & $56 \mathrm{G}, 2 \mathrm{D}$ \\
\hline & 12. South Korea (6) & $6 \mathrm{D}$ \\
\hline & 13. Sri Lanka (4) & $2 \mathrm{G}, 2 \mathrm{D}$ \\
\hline & 14. Taiwan (31) & $13 \mathrm{G}, 18 \mathrm{D}$ \\
\hline & 15. Thailand (63) & $11 \mathrm{G}, 52 \mathrm{D}$ \\
\hline & 16. Vietnam (2) & $2 \mathrm{D}$ \\
\hline & 17. Israel (2) & $1 \mathrm{G}, 1 \mathrm{D}$ \\
\hline Total: 1017 & & $\begin{array}{l}744 G(73.2 \%) \\
273 D(26.8 \%)\end{array}$ \\
\hline Africa (103) & 1. Egypt (83) & 79G,2D,2X \\
\hline & 2. Morocco (10) & $10 \mathrm{G}$ \\
\hline & 3. Tunisia (8) & $5 \mathrm{G}, 3 \mathrm{D}$ \\
\hline & 4. Kenya (2) & $1 \mathrm{G}, 1 \mathrm{D}$ \\
\hline Total: 103 & & $\begin{array}{l}95 G(92.2 \%) \\
6 D(5.8 \%)\end{array}$ \\
\hline Europe (441) & 1. Czech Republic (23) & $23 \mathrm{G}$ \\
\hline & 2. France (85) & $65 \mathrm{G}, 20 \mathrm{D}$ \\
\hline & 3. Germany (79) & $55 \mathrm{G}, 22 \mathrm{D}, 2 \mathrm{X}$ \\
\hline & 4. Greece (98) & 77G,21D \\
\hline & 5. Italy (14) & $11 \mathrm{G}, 3 \mathrm{D}$ \\
\hline & 6. Poland (31) & $30 \mathrm{G}, 1 \mathrm{D}$ \\
\hline & 7. Russia (8) & $7 \mathrm{G}, 1 \mathrm{D}$ \\
\hline & 8. Serbia (11) & $11 \mathrm{G}$ \\
\hline & 9. Spain (37) & 16G,21D \\
\hline & 10. Turkey (55) & $54 \mathrm{G}, 1 \mathrm{D}$ \\
\hline Total: 441 & & $\begin{array}{l}\text { 349G }(79.1 \%) \\
\text { 90D (20.4\%) }\end{array}$ \\
\hline Oceania $(142$ & ) 1. Australia (1423) & $953 \mathrm{G}, 459 \mathrm{D}, 11 \mathrm{X}$ \\
\hline & 2. Guam (3) & $3 \mathrm{D}$ \\
\hline Total: 1426 & & $\begin{array}{l}953 G(66.8 \%) \\
462 D(32.4 \%)\end{array}$ \\
\hline $\begin{array}{l}\text { North Americ } \\
(\mathbf{8 5 6 4 )}\end{array}$ & 1. USA (8544) & $\begin{array}{l}6313 \mathrm{G}, 2200 \mathrm{D} \\
31 \mathrm{X}\end{array}$ \\
\hline & 2. Puerto Rico (12) & $9 \mathrm{G}, 3 \mathrm{D}$ \\
\hline & 3. Jamaica (8) & $3 \mathrm{G}, 5 \mathrm{D}$ \\
\hline Total: 8564 & & $\begin{array}{l}6325 G(73.9 \%) \\
2208 D(25.8 \%)\end{array}$ \\
\hline $\begin{array}{l}\text { South Ameri } \\
\text { (20) }\end{array}$ & 1. Brazil (6) & $4 \mathrm{G}, 2 \mathrm{D}$ \\
\hline & 2. Chile (11) & 9G,2D \\
\hline & 3. Colombia (3) & $1 \mathrm{G}, 2 \mathrm{D}$ \\
\hline Total: 20 & & $\begin{array}{l}14 G(70 \%) \\
6 D(30 \%)\end{array}$ \\
\hline
\end{tabular}



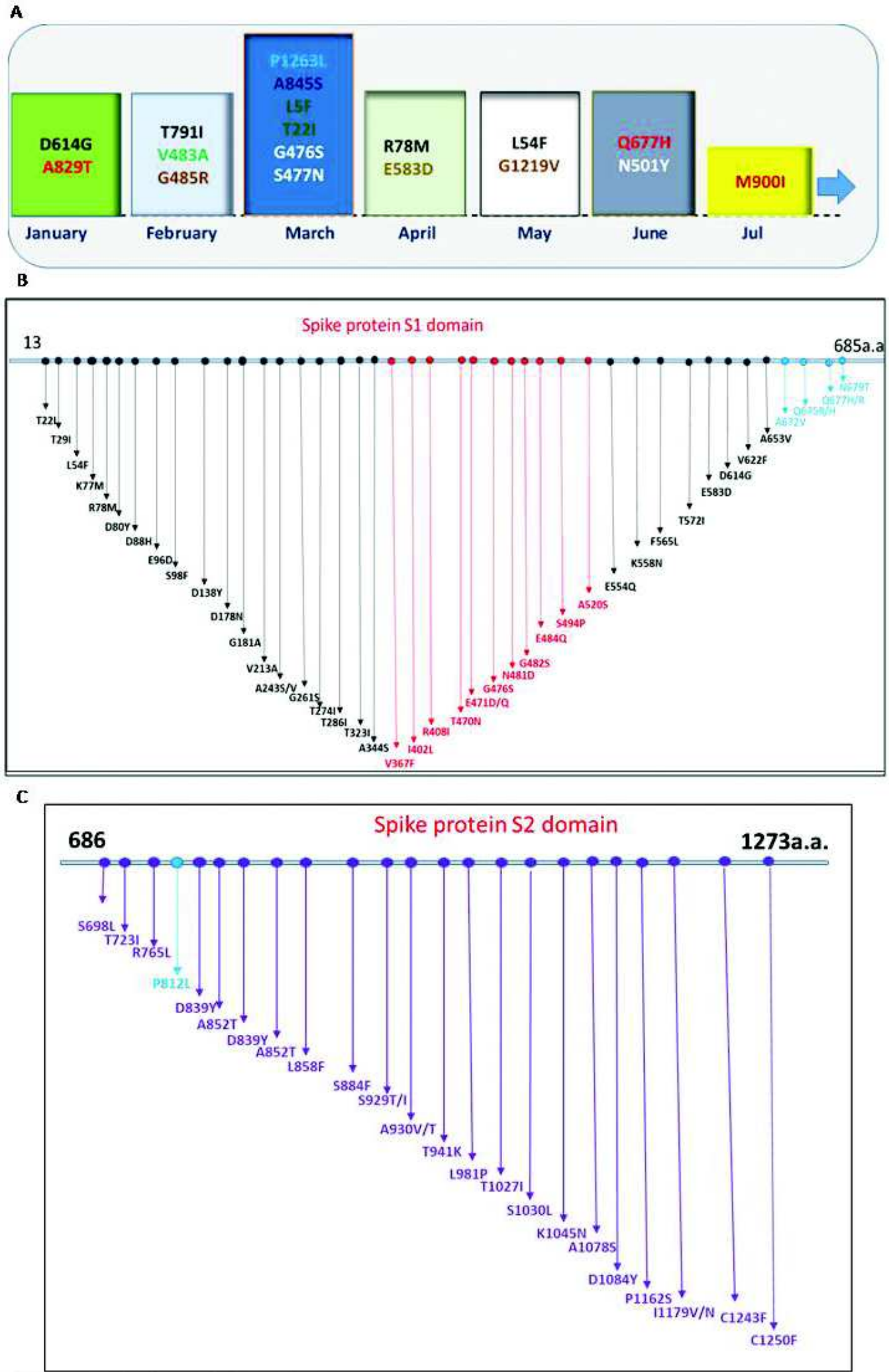

Fig. 2: Mutations of spike protein. A. The different major mutations are shown in terms of its first occurrence (i.e. with respect to the collection time) at different months of the year 2020; B. Mutations in S1 domain of SARS-CoV-2 Spike protein in Indian Isolates. Red dots indicate mutations in RBD region. Blue dots signify mutations near the S1S2 cleavage site; C. Mutations in S2 domain of SARS-CoV-2 Spike protein in Indian Isolates. Blue dots indicate mutations in the S2' cleavage site 


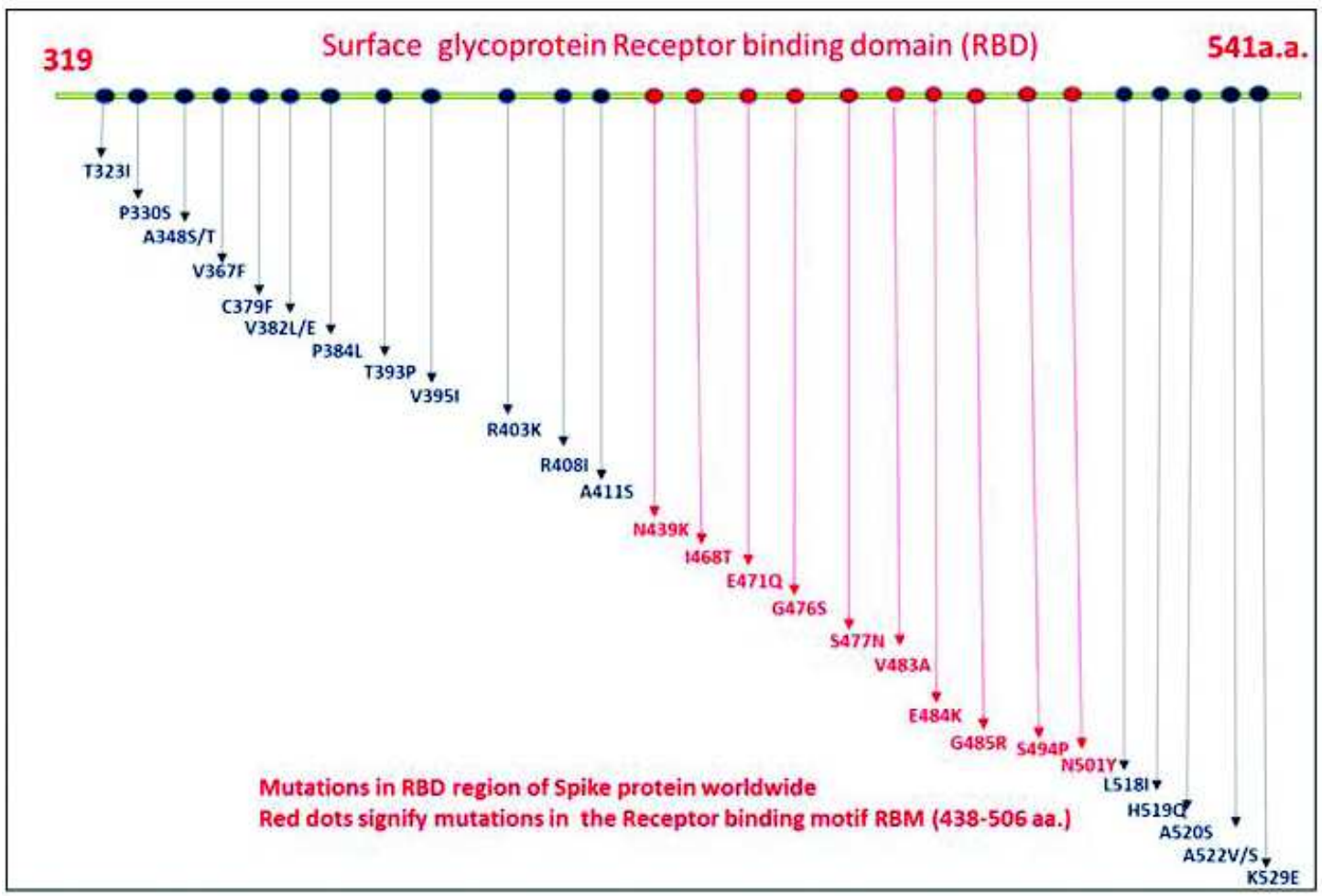

Fig. 3: Positions of mutations in receptor binding domain (RBD). Mutations in RBD region of Spike protein worldwide. Red dots signify mutations in the Receptor binding motif RBM (438-506 aa)

Table 4: Mutational analysis of Receptor binding domain (RBD) of SARS-CoV2 Spike protein

\begin{tabular}{|c|c|c|}
\hline $\begin{array}{l}\text { Major mutations in receptor } \\
\text { binding region (RBD) of spike }\end{array}$ & Continents (Total number of sequences) & Percentage of sequences showing the mutation \\
\hline S477N & $\begin{array}{l}\text { 1. Asia (1017) } \\
\text { 2. Africa (103) } \\
\text { 3. Europe (441) } \\
\text { 4. North America (8564) } \\
\text { 5. South America (20) } \\
\text { 6. Oceania (1426) }\end{array}$ & $\begin{array}{l}1015 \mathrm{~S}(99.8 \%), 1 \mathrm{X}, 1 \mathrm{G} \\
103 \mathrm{~S}(100 \%) \\
422 \mathrm{~S}(95.7 \%), 19 \mathrm{X} \\
8493 \mathrm{~S}(99.2 \%), 3 \mathrm{~N}(0.04 \%), \\
68 \mathrm{X} 20 \mathrm{~S}(100 \%) \\
1087 \mathrm{~S}(76.2 \%), 59 \mathrm{~N}(4.1 \%), 280 \mathrm{X}\end{array}$ \\
\hline G485R & $\begin{array}{l}\text { 1. Asia (1017) } \\
\text { 2. Africa (103) } \\
\text { 3. Europe (441) } \\
\text { 4. North America (8564) } \\
\text { 5. South America (20) } \\
\text { 6. Oceania (1426) }\end{array}$ & $\begin{array}{l}\text { 1016G }(99.9 \%), 1 \mathrm{R}(0.01 \%) \\
103 \mathrm{G}(100 \%) \\
423 \mathrm{G}(95.9 \%), 18 \mathrm{X} \\
8514 \mathrm{G}(99.6 \%), 50 \mathrm{X} \\
20 \mathrm{G}(100 \%) \\
1086 \mathrm{G}(76.2 \%), 31 \mathrm{R}(2.2 \%), 306 \mathrm{X}\end{array}$ \\
\hline
\end{tabular}

\begin{tabular}{|c|c|c|}
\hline \multirow[t]{6}{*}{ N501Y } & 1. Asia (1017) & $1017 \mathrm{~N}(100 \%)$ \\
\hline & 2. Africa (103) & $103 \mathrm{~N}(100 \%)$ \\
\hline & 3. Europe (441) & $423 \mathrm{~N}(95.9 \%), 18 \mathrm{X}$ \\
\hline & 4. North America (8564) & $8499 \mathrm{~N}(99.5 \%), 65 \mathrm{X}$ \\
\hline & 5. South America (20) & $20 \mathrm{~N}(100 \%)$ \\
\hline & 6. Oceania (1426) & $1096 \mathrm{~N}(76.9 \%), 14 \mathrm{Y}(1.0 \%), 313 \mathrm{X}$ \\
\hline
\end{tabular}




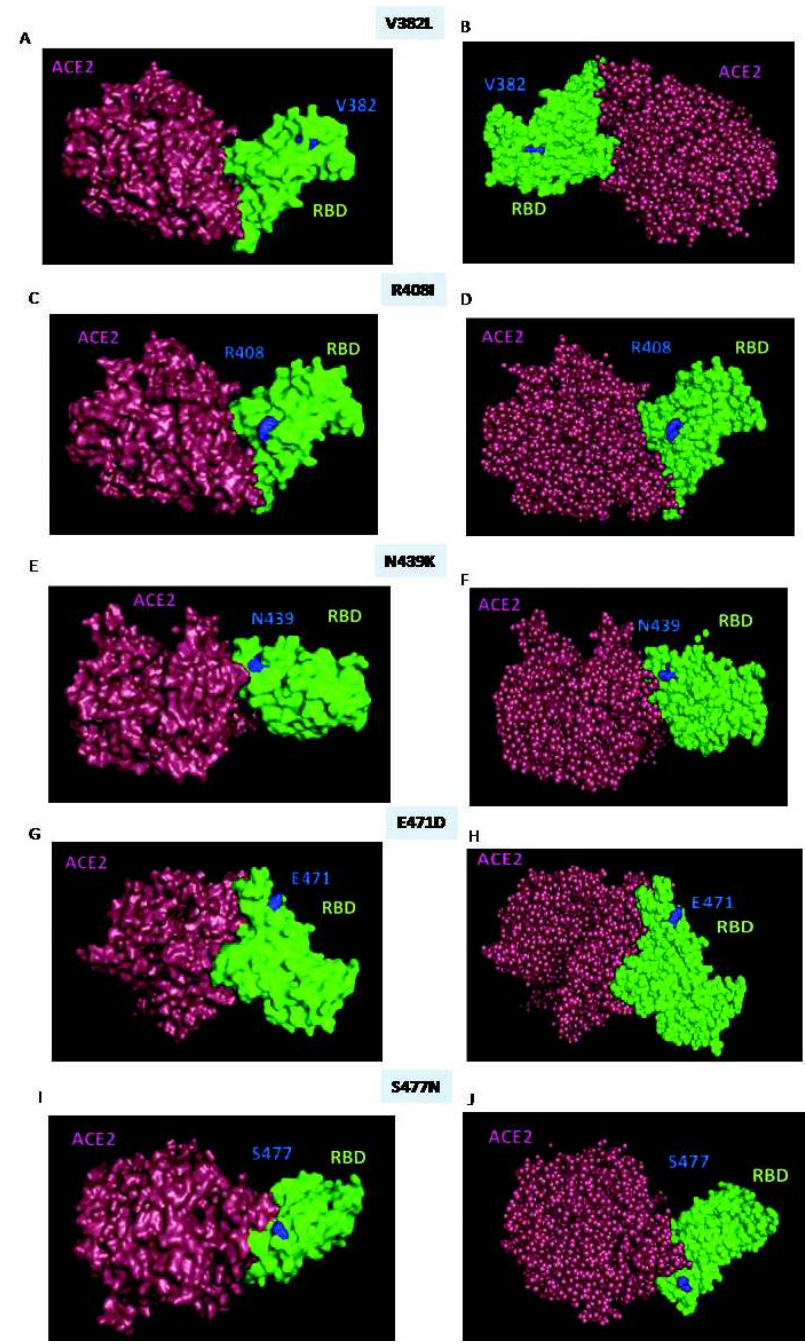

Fig. 4: RBD mutations. PDB ID:6lzg has been used to indicate the position of the mutations (A-B: position 382; C-D: position 408; E-F: position 439; G-H: position 471; I-J: position 477). Structure in maroon colour indicates $A C E$ receptor and that in green colour represents RBD. Mutation points are shown in blue

at a very slow pace. Similarly, in the current analyses which involved multiple continents, nearly 25 minor mutations were observed in the RBD region (Table 6) which have very low frequency of occurrence in the total sequence studied. Some of these mutations like $\mathrm{N} 439 \mathrm{~K}$ was detected in samples collected in the month of July, 2020 and thus more sequencing results that eventually gets deposited over next few months might shed light on the possibility of selection of such mutations and role in virus evolution.

To check the molecular location of the mutation sites of RBD with respect to the ACE2 receptor
Table 5: Major mutations in receptor binding domain (RBD) of the spike protein based on the relative number of times the mutation appeared in each country (as shown in Table 4) and the collection dates of each sample. 3 mutations that were reported earlier have also been included here although the percentage of occurrence is low

\begin{tabular}{|c|c|c|}
\hline $\begin{array}{l}\text { Mutations } \\
\text { in the RBD } \\
\text { domain } \\
\text { (Major) } \\
\text { (NCBI ID: } \\
\text { YP_00972- } \\
4390.1 \text { ) }\end{array}$ & $\begin{array}{l}\text { NCBI Accession ID } \\
\text { of the Spike protein } \\
\text { mutation is detected }\end{array}$ & $\begin{array}{l}\text { Collection date of the } \\
\text { sequence where the } \\
\text { patient samples used } \\
\text { for sequencing } \\
\text { (year-month-day) } \\
\text { (as per availability of } \\
\text { data) }\end{array}$ \\
\hline \multirow[t]{10}{*}{ 1. G476S } & 1. QJC20487.1 & 1. $2020-03-27$ \\
\hline & 2. QKS90479.1 & 2. $2020-03-02$ \\
\hline & 3. QKS90179.1 & 3. $2020-03-02$ \\
\hline & 4. QJD48075.1 & 4. $2020-03-10$ \\
\hline & 5. QJA16664.1 & 5. $2020-03-25$ \\
\hline & 6. QIS30625.1 & 6. $2020-03-15$ \\
\hline & 7. QIS30425.1 & 7. $2020-03-14$ \\
\hline & 8. QIZ13371.1 & 8. $2020-03-21$ \\
\hline & 9. QIQ50152.1 & 9. $2020-03-14$ \\
\hline & 10. QIQ49882.1 & 10. $2020-03-13$ \\
\hline
\end{tabular}

\section{S477NA.}

\begin{tabular}{lll} 
1. QLustralia & 1.2020-06-11 \\
2. QLG76673.1 & 2. 2020-06-13 \\
3. QLG75581.1 & $3.2020-05-30$ \\
4. QLG75569.1 & 4. 2020-05-30 \\
5. QLG76949.1 & $5.2020-06-18$ \\
6. QLG76409.1 & 6. 2020-06-19 \\
7. QLG76925.1 & 7.2020 \\
8. QLG76901.1 & $8.2020-06-19$ \\
9. QLG76889.1 & $9.2020-03-19$ \\
10. QLG76877.1 & $10.2020-06-19$ \\
11. QLG76841.1 & $11.2020-06-15$ \\
12. QLG76829.1 & $12.2020-06-16$ \\
13. QLG76781.1 & $13.2020-06-15$ \\
14. QLG76769.1 & $14.2020-06-15$ \\
15. QLG76757.1 & $15.2020-06-14$ \\
16. QLG76733.1 & $16.2020-06-13$ \\
17. QLG76721.1 & $17.2020-06-14$ \\
18. QLG76661.1 & $18.2020-06-13$ \\
19. QLG76649.1 & $19.2020-06-13$ \\
20. QLG76637.1 & $20.2020-06-12$ \\
21. QLG76625.1 & $21.2020-06-10$ \\
22. QLG76613.1 & $22.2020-06-09$ \\
\hline
\end{tabular}




\begin{tabular}{|c|c|c|}
\hline & 23. QLG76601.1 & 23. $2020-06-08$ \\
\hline & 24. QLG76493.1 & 24. $2020-06-20$ \\
\hline & 25. QLG76481.1 & $25.2020-06-19$ \\
\hline & 26. QLG76445.1 & 26. 2020-06-19 \\
\hline & 27. QLG76433.1 & 27. 2020-06-19 \\
\hline & 28. QLG76421.1 & 28. 2020-06-19 \\
\hline & 29. QLG76349.1 & 29. $2020-06-18$ \\
\hline & 30. QLG76325.1 & 30. 2020-06-17 \\
\hline & 31. QLG76301.1 & 31. 2020-06-15 \\
\hline & 32. QLG76229.1 & 32. $2020-06-15$ \\
\hline & 33. QLG76217.1 & 33. $2020-06-15$ \\
\hline & 34. QLG76205.1 & 34. $2020-06-15$ \\
\hline & 35. QLG76193.1 & $35.2020-06-15$ \\
\hline & 36. QLG76169.1 & 36. $2020-06-15$ \\
\hline & 37. QLG76061.1 & 37. $2020-06-13$ \\
\hline & 38. QLG76001.1 & 38. 2020-06-12 \\
\hline & 39. QLG75989.1 & 39. 2020-06-11 \\
\hline & 40. QLG75881.1 & 40. 2020-06-09 \\
\hline & 41. QLG75797.1 & 41. 2020-06-05 \\
\hline & 42. QLG75713.1 & 42. $2020-05-27$ \\
\hline & 43. QLG75557.1 & 43. $2020-05-30$ \\
\hline & 44. QLG76865.1 & 44. $2020-06-17$ \\
\hline & 45. QLG76073.1 & 45. 2020-06-12 \\
\hline & 46. QLG75593.1 & 46. $2020-05-29$ \\
\hline & 47. QKR86413.1 & 47. $2020-05-16$ \\
\hline & 48. QKR85873.1 & 48. $2020-05-13$ \\
\hline & 49. QKR86845.1 & 49. $2020-05-19$ \\
\hline & 50. QKR86809.1 & 50. $2020-05-19$ \\
\hline & 51. QLG75641.1 & 51. $2020-05-30$ \\
\hline & 52. QLG75605.1 & 52. 2020-06-01 \\
\hline & 53. QLG75449.1 & 53. $2020-05-28$ \\
\hline & 54. QLG75437.1 & 54. $2020-05-29$ \\
\hline & 55. QLG75389.1 & 55. $2020-05-28$ \\
\hline & 56. QKR86857.1 & 56. $2020-05-19$ \\
\hline & 57. QKR86821.1 & 57. $2020-05-19$ \\
\hline & 58. QKR87133.1 & 58. $2020-05-26$ \\
\hline & 59. QKR86425.1 & 59. 2020-05-16 \\
\hline \multirow[t]{3}{*}{ B. USA } & 1. QLC46901.1 & 1. $2020-04-21$ \\
\hline & 2. QJZ32245.1 & 2. $2020-04-12$ \\
\hline & 3. QKG90206.1 & 3. $2020-03-28$ \\
\hline \multirow[t]{3}{*}{ 3. V483A } & 1. QIZ13131.1 & 1. $2020-03-23$ \\
\hline & 2. QKV06535.1 & 2. $2020-03-24$ \\
\hline & 3. QKU54117.1 & 3. $2020-03-12$ \\
\hline
\end{tabular}

\begin{tabular}{ll}
\hline 4. QKU54081.1 & 4. 2020-03-12 \\
5. QKU53649.1 & 5. 2020-03-17 \\
6. QKS91079.1 & $6.2020-03-02$ \\
7. QKS90659.1 & 7. 2020-03-02 \\
8. QKS90239.1 & 8. 2020-03-01 \\
9. QKS90227.1 & $9.2020-02-29$ \\
10. QKS90095.1 & $10.2020-03-05$ \\
11. QKS90059.1 & $11.2020-03-02$ \\
12. QKS90023.1 & $12.2020-03-02$ \\
13. QKS89879.1 & $13.2020-02-29$ \\
14. QJD49095.1 & $14.2020-03-05$ \\
15. QJD48987.1 & $15.2020-03-09$ \\
16. QIZ14939.1 & $16.2020-03-16$ \\
17. QIU81549.1 & $17.2020-03-19$ \\
18. QIU81177.1 & $18.2020-03-16$ \\
19. QIS60954.1 & $19.2020-03-16$ \\
20. QIS60882.1 & $20.2020-03-16$ \\
21. QIS60774.1 & $21.2020-03-16$ \\
22. QIS30565.1 & $22.2020-03-15$ \\
23. QIS30165.1 & $23.2020-03-16$ \\
24. QJS57147.1 & $24.2020-04-05$ \\
QKU53733.1 & $2020-03-17$ \\
\hline
\end{tabular}

\section{G485R}

$\begin{array}{ccc}\text { A. Australia } & \text { 1. QKR85573.1 } & \text { 2. 2020-05-05 } \\ \text { 2. QKR86245.1 } & \text { 3. 2020-05-12 } \\ \text { 3. QKR86185.1 } & \text { 4. 2020-05-12 } \\ \text { 4. QKR85609.1 } & 5.2020-05-05 \\ \text { 5. QKR86449.1 } & \text { 6. 2020-05-17 } \\ \text { 6. QLG75965.1 } & \text { 7. 2020-06-10 } \\ \text { 7. QKR86221.1 } & \text { 8. 2020-05-12 } \\ \text { 8. QLG75509.1 } & \text { 9.2020-05-28 } \\ \text { 9. QKR86785.1 } & 10.2020-05-18 \\ \text { 10. QKR86881.1 } & 11.2020-05-17 \\ \text { 11. QKR86233.1 } & 12.2020-05-12 \\ \text { 12. QKR86353.1 } & 13.2020-05-09 \\ \text { 13. QKR86197.1 } & 14.2020-05-12 \\ \text { 14. QKR86089.1 } & 15.2020-05-09 \\ \text { 15. QKR85825.1 } & 16.2020-05-05 \\ \text { 16. QLG75773.1 } & 17.2020-06-03 \\ \text { 17. QKR85945.1 } & 18.2020-05-05 \\ \text { 18. QKR87169.1 } & 19.2020-05-24 \\ \text { 19. QKR86389.1 } & 20.2020-05-14 \\ \text { 20. QLG75461.1 } & 21.2020-05-27 \\ \text { 21. QKR86497.1 } & 22.2020-05-17\end{array}$




\begin{tabular}{ll} 
22. QKR86365.1 & 23. 2020-05-12 \\
23. QKR86341.1 & 24. 2020-05-12 \\
24. QKR86209.1 & 25. 2020-05-12 \\
25. QKR85909.1 & 26. 2020-05-14 \\
26. QKR85597.1 & 27. 2020 \\
27. QKR85513.1 & 28. 2020-05-05 \\
28. QKR85381.1 & 29.2020-05-05 \\
29. QKR85765.1 & $30.2020-05-09$ \\
30. QLG75497.1 & $31.2020-05-27$ \\
31. QKR85453.1 & 32.2020 \\
1. QJG65949.1 & $1.2020-02-06$ \\
1. QLG76745.1 & $1.2020-06-16$ \\
2. QLG76805.1 & $2.2020-06-18$ \\
3. QLG76793.1 & $3.2020-06-17$ \\
4. QLG76709.1 & $4.2020-06-12$ \\
5. QLG76697.1 & $5.2020-06-12$ \\
6. QLG76685.1 & $6.2020-06-15$ \\
7. QLG76469.1 & 7. 2020-06-18 \\
8. QLG76397.1 & 8. 2020-06-19 \\
9. QLG76277.1 & $9.2020-06-17$ \\
10. QLG76181.1 & $10.2020-06-15$ \\
11. QLG76097.1 & $11.2020-06-14$ \\
12. QLG76085.1 & $12.2020-06-12$ \\
13. QLG75761.1 & $13.2020-06-03$ \\
\hline
\end{tabular}
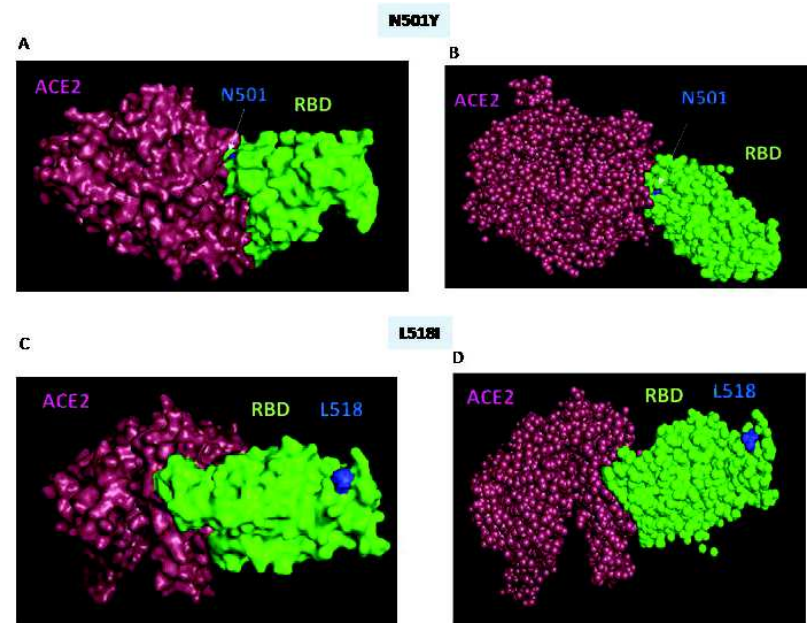

L5189

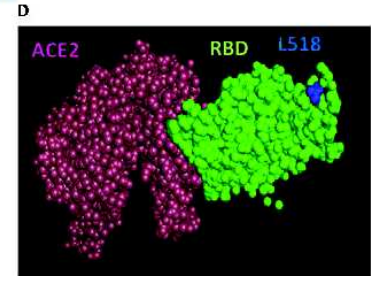

Fig. 6: RBD mutations. PDB ID:6lzg has been used to indicate the position of the mutations (A-B: position 501; C-D: position 518). Structure in maroon colour indicates ACE receptor and that in green colour represents RBD. Mutation points are shown in blue binding interface, we checked eleven of the RBD mutation sites on the RBD-ACE2 complex structure from PDB (Figs. 4-6). Most of the major RBD mutations (except L518I) lie in the receptor binding motif(RBM) of the spike protein, the residues of which directly interact with the ACE2 receptor. As per the
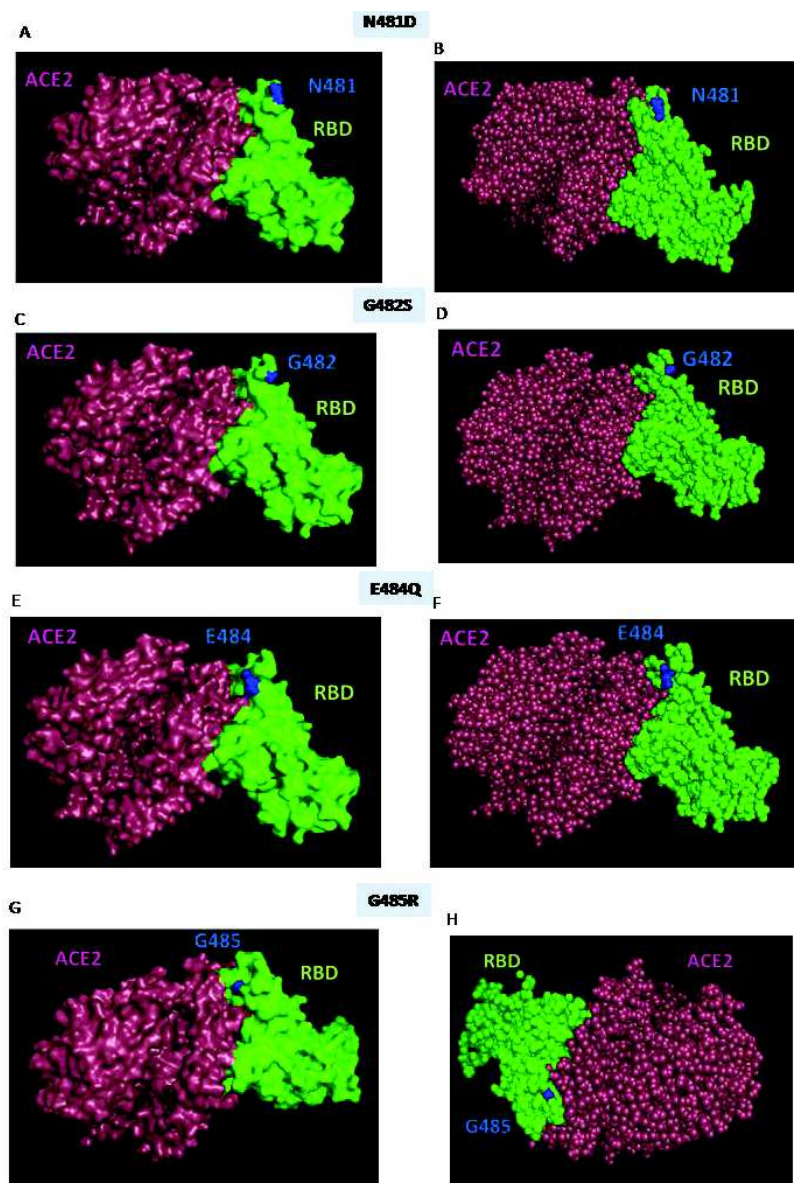

Fig. 5: RBD mutations. PDB ID:6lzg has been used to indicate the position of the mutations (A-B: position 481; C-D: position 482; E-F: position 484; G-H: position 485). Structure in maroon colour indicates $A C E$ receptor and that in green colour represents RBD. Mutation points are shown in blue

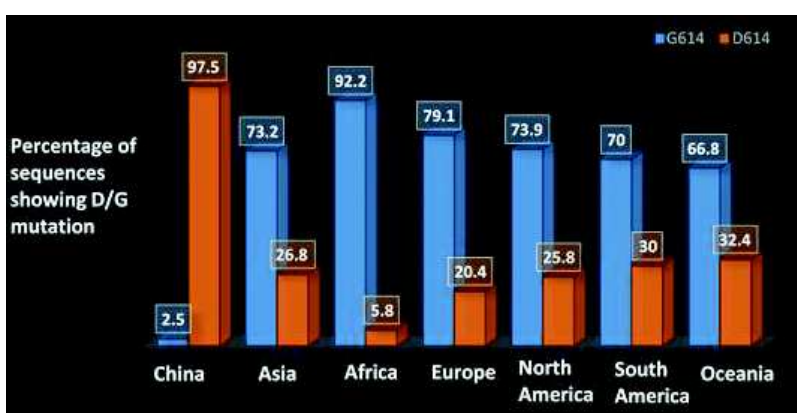

Fig. 7: Distribution pattern of mutation D614G across different continents 
A

Prediction Outcome of Dynakut Prediction
AAG:1.793 kcalhol (Strabilizing mutation)

NMA Based Predictions

MGENCoM: 4211 kcalhnol (Stabilizing)

$\triangle$ Vhrational Entropy Energy Between Wad-Type and Lutant

MAS $\mathrm{VNCoM}_{\mathrm{i}}-4.764 \mathrm{kcal}_{\mathrm{mol}}^{-1} \mathrm{~K}^{-1}$ (Decrease of molecule flexibility)

B

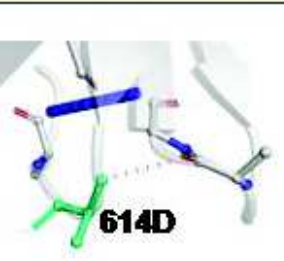

Wid-type

C

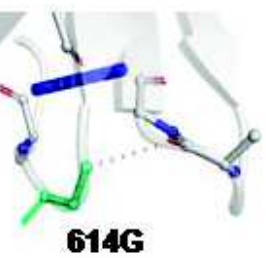

D614Gmutant

D

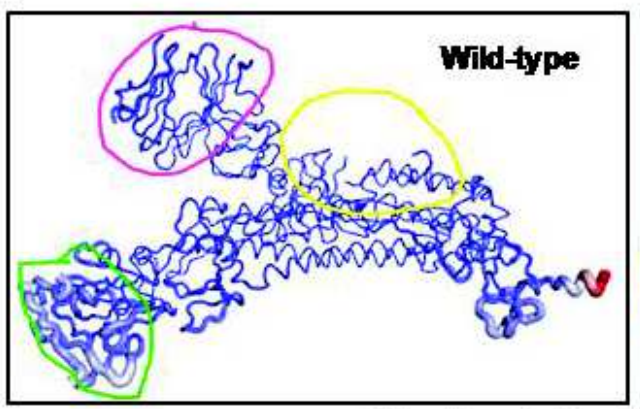

\begin{abstract}
Bond Type
Hydrogen bonds

Water mediated hydrogen bonds

Weak hydrogen bonds

Halogen bonds

Ionic interactions

Metal complex interactions

Aromatic contacts

Hydrophobic contacts
\end{abstract}

Water mediated weak hydrogen bonds

Carbonyl contacts

E

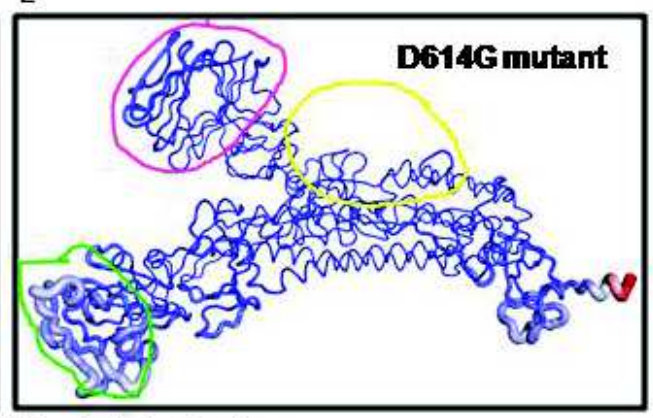

Visualanahsis of Atomic Fluctuation

Magnitude of the fluctuation: blue (low), white (moderate) and red (high)

$\mathrm{F}$

$\mathbf{G}$

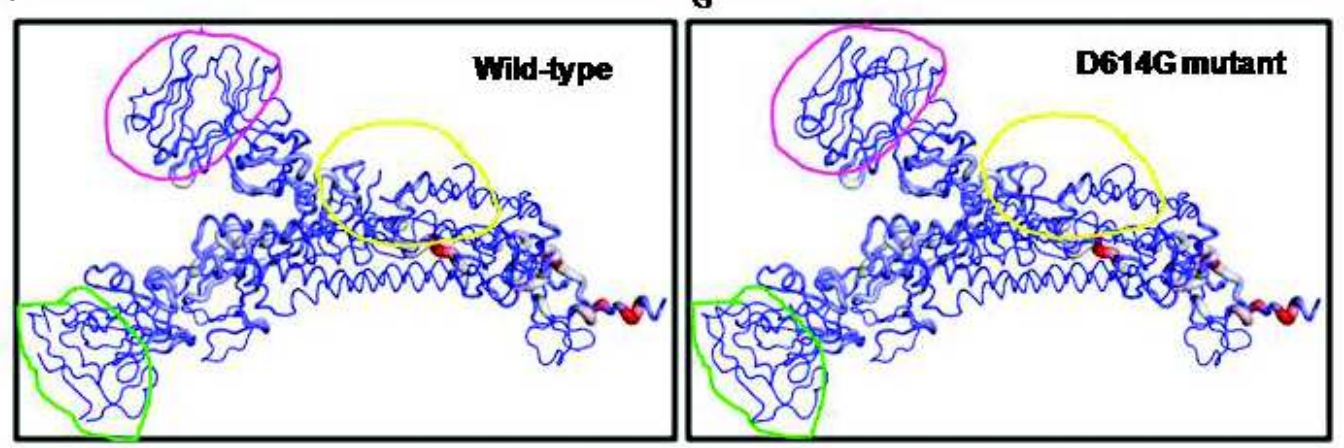

Visualanalysis of Deformation Energies

Magnitude of the deformation: blue (low), white (moderate) and red (high)

Fig. 8: DynaMut prediction of effect of D614G mutation on Spike protein. A. Entropy and free energy changes as assessed by the DynaMut prediction for D614G mutation B. Inermolecular interactions in wild-type spike protein at position 614. C. Inermolecular interactions in mutant spike protein at position 614. D-E Visual analysis of atomic fluctuations.FG.Inermolecular interactions in mutant spike protein at position 614. D-E Visual analysis of deformation energies 
Table 6: Tabulation of all the minor mutations that are detected in the Receptor binding domain (RBD) of the Spike protein

\begin{tabular}{|c|c|c|c|}
\hline $\begin{array}{l}\text { RBD Mutations } \\
\text { (Minor) }\end{array}$ & $\begin{array}{l}\text { Country of origin (percentage of } \\
\text { sequences showing the mutation) }\end{array}$ & $\begin{array}{l}\text { NCBI Accession ID of the } \\
\text { sequence showing the mutation }\end{array}$ & $\begin{array}{l}\text { Collection date of the patient } \\
\text { samples where mutation is } \\
\text { detected (year-month-day) }\end{array}$ \\
\hline \multirow[t]{3}{*}{ 1. T323I } & \multirow[t]{3}{*}{ USA (8396T, 3I, 145X) $(0.04 \%)$} & a. QLK98059.1 & 2020-04-10 \\
\hline & & b. QKV06079.1 & $2020-03-27$ \\
\hline & & c. QJD25193.1 & $2020-03-21$ \\
\hline \multirow[t]{2}{*}{ 2. P330S } & \multirow[t]{2}{*}{ USA (8515P, 2S, 27X) $(0.02 \%)$} & a. QKV37091.1 & 2020-04-17 \\
\hline & & b. QKV37031.1 & $2020-04-17$ \\
\hline 3. A348S & USA (8518A,1S,25X) (0.01\%) & a. QKU32465.1 & $2020-05-02$ \\
\hline 4. $\mathrm{A348T}$ & USA (8538A 1T ,25X) (0.01\%) & a. QIS30335.1 & $2020-03-16$ \\
\hline 5. V367F & China $(120 \mathrm{~V}, 1 \mathrm{~F})(0.8 \%)$ & a. QJC20993.1 & $2020-01-22$ \\
\hline 6. C379F & France $(84 \mathrm{C}, 1 \mathrm{~F})(1.2 \%)$ & a. QJT72386.1 & $2020-03$ \\
\hline 7. V382L & USA $(8509 \mathrm{~V}, 1 \mathrm{~L}, 34 \mathrm{X})(0.01 \%)$ & a. QLG98191.1 & 2020-06-03 \\
\hline 8. V382E & France $(84 \mathrm{~V}, 1 \mathrm{E})(1.2 \%)$ & a. QJT72806.1 & $2020-03$ \\
\hline \multirow[t]{2}{*}{ 9. P384L } & \multirow[t]{2}{*}{ USA (8504P,2L,39X) $(0.02 \%)$} & a. QKO24139.1 & $2020-05-04$ \\
\hline & & b. QKV08239.1 & 2020-04-05 \\
\hline 10. T393P & Greece $(97 \mathrm{~T}, 1 \mathrm{P})(1 \%)$ & a. QJS54106.1 & $2020-03-29$ \\
\hline \multirow[t]{2}{*}{ 11. V395I } & \multirow[t]{2}{*}{ USA $(8501 \mathrm{~V}, 2 \mathrm{I}, 41 \mathrm{X})(0.02 \%)$} & a. QMI95674.1 & $2020-03-15$ \\
\hline & & b. QMI90807.1 & $2020-03-15$ \\
\hline \multirow[t]{10}{*}{ 12. R403K } & \multirow[t]{9}{*}{ A. USA (8503R, 9K,32X) $(0.1 \%)$} & a. QLA47931.1 & $2020-05$ \\
\hline & & b. QLA47919.1 & $2020-05$ \\
\hline & & c. QLA47907.1 & $2020-05$ \\
\hline & & d. QLA47895.1 & $2020-05$ \\
\hline & & e. QLA47883.1 & $2020-05$ \\
\hline & & f. QLA47799.1 & $2020-05$ \\
\hline & & g. QLA47787.1 & $2020-05$ \\
\hline & & h. QLA47775.1 & $2020-05$ \\
\hline & & i. QLL36145.1 & $2020-04$ \\
\hline & Australia $(1420 \mathrm{R}, 1 \mathrm{~K}, 2 \mathrm{X})(0.07 \%)$ & a. QKR87157.1 & $2020-05-27$ \\
\hline \multirow[t]{3}{*}{ 13. R408I } & A. Egypt $(79 R, 2 I, 2 X)(2.4 \%)$ & a. QKT21014.1 & 2020-06-02 \\
\hline & \multirow[t]{2}{*}{ B. India $(454 \mathrm{R}, 1 \mathrm{I})(0.2 \%)$} & b. QJY78056.1 & $2020-05-02$ \\
\hline & & a. QHS34546.1 & $2020-01-27$ \\
\hline \multirow[t]{6}{*}{ 14. A411S } & USA (San Diego, California) & a. QMI96187.1 & 2020-04-29 \\
\hline & \multirow[t]{5}{*}{$(8497 \mathrm{~A}, 6 \mathrm{~S}, 41 \mathrm{X})(0.07 \%)$} & b. QMI93578.1 & $2020-05-03$ \\
\hline & & c. QMI93554.1 & $2020-05-03$ \\
\hline & & d. QMI93410.1 & $2020-05-06$ \\
\hline & & e. QMI93230.1 & $2020-05-05$ \\
\hline & & f. QMI93158.1 & $2020-05-06$ \\
\hline 15. N439K & USA $(8472 \mathrm{~N}, 1 \mathrm{~K}, 71 \mathrm{X})(0.01 \%)$ & a. QLM06051.1 & 2020-07-07 \\
\hline 16. I468T & Australia(1146I,1T,276)(0.07\%) & a. QJR86937.1 & $2020-03-18$ \\
\hline 17. E471Q & India (454E,1Q) $(0.2 \%)$ & a. QJX44562.1 & $2020-05-04$ \\
\hline 18. E484K & USA $(8490 \mathrm{E}, 1 \mathrm{~K}, 53 \mathrm{X})(0.01 \%)$ & a. QLI51445.1 & $2020-05-22$ \\
\hline
\end{tabular}




\begin{tabular}{|c|c|c|c|}
\hline \multirow[t]{3}{*}{ 19. S494P } & USA $(8474 \mathrm{~S}, 3 \mathrm{P}, 67 \mathrm{X})(0.04 \%)$ & a. QJF75359.1 & $2020-03-20$ \\
\hline & & b. QJF75347.1 & $2020-03-20$ \\
\hline & & c. QJF75335.1 & $2020-03-20$ \\
\hline \multirow[t]{3}{*}{ 20. L518I } & Bangladesh (168L,3I) (1.8\%) & a. QLE10873.1 & $2020-06-24$ \\
\hline & & b. QLE10825.1 & $2020-06-16$ \\
\hline & & c. QLE10753.1 & $2020-06-18$ \\
\hline \multirow[t]{3}{*}{ 21. H519Q } & A. Australia $(1031 \mathrm{H}, 2 \mathrm{Q}, 390 \mathrm{X})(0.14 \%)$ & a. QKR85081.1 & $2020-04-27$ \\
\hline & B. Malaysia $(3 \mathrm{H}, 1 \mathrm{Q})(25 \%)$ & b. QKR86401.1 & $2020-05-17$ \\
\hline & & a. QJD23249.1 & $2020-03-20$ \\
\hline \multirow[t]{6}{*}{ 22. A520S } & USA $(8473 \mathrm{~A}, 6 \mathrm{~S}, 65 \mathrm{X})(0.07 \%)$ & a. QJA41737.1 & 2020-03-19 \\
\hline & & b. QIS60489.1 & $2020-03-13$ \\
\hline & & c. QKU53949.1 & 2020-03-19 \\
\hline & & d. QKU53925.1 & $2020-03-13$ \\
\hline & & e. QKU53817.1 & 2020-03-19 \\
\hline & & f. QJU70545.1 & $2020-04-26$ \\
\hline 23. A522V & USA $(8490 \mathrm{~A}, 1 \mathrm{~V}, 53 \mathrm{X})(0.01 \%)$ & a. QKU28906.1 & $2020-04-12$ \\
\hline 24. A522S & Australia $(1052 \mathrm{~A}, 1 \mathrm{~S}, 370 \mathrm{X})(0.01 \%)$ & a. QJR91593.1 & $2020-03-27$ \\
\hline 25. K529E & USA $(8532 \mathrm{~K}, 1 \mathrm{E}, 11 \mathrm{X})(0.01 \%)$ & a. QJC20043.1 & $2020-03-26$ \\
\hline
\end{tabular}

Table 7: Mutational analysis of the SARS-CoV2 Surface glycoproteins from Indian isolates. Mutation highlighted in yellow is the one detected in China as well in the month of January. Mutations highlighted in green are new mutations that were detected in the patient samples collected in the month of June and July 2020. Mutations highlighted in blue are the ones lying close to the $S 1 / S 2$ (furin) cleavage site $\left(681^{\text {st }}-684^{\text {th }}\right)$ and $S 2$ ' cleavage site $\left(811^{\text {th }}-815^{\text {th }}\right)$

\begin{tabular}{|c|c|c|c|}
\hline $\begin{array}{l}\text { Mutations in SARS-CoV2 } \\
\text { surface glycoprotein in } \\
\text { Indian isolates }\end{array}$ & $\begin{array}{l}\text { Percentage of sequences } \\
\text { showing the mutation } \\
\text { (Total number of sequences }=1648 \text { ) }\end{array}$ & $\begin{array}{l}\text { GISAID Accession ID of the } \\
\text { respective sequence showing } \\
\text { the mutation }\end{array}$ & $\begin{array}{l}\text { Collection date } \\
\text { (year-month-day) }\end{array}$ \\
\hline \multirow[t]{9}{*}{ 1. L5F } & $1639 \mathrm{~L}$ & 1.EPI_ISL_435108 & 1. $2020-03-15$ \\
\hline & \multirow[t]{8}{*}{$9 \mathrm{~F}(0.55 \%)$} & 2.EPI_ISL_463033 & 2. $2020-05-10$ \\
\hline & & 3. EPI_ISL_455756 & 3. $2020-05-07$ \\
\hline & & 4. EPI_ISL_451150 & 4. $2020-05-06$ \\
\hline & & 5.EPI_ISL_451151 & 5. $2020-05-05$ \\
\hline & & 6. EPI_ISL_458103 & 6. 2020-05-05 \\
\hline & & 7. EPI_ISL_495290 & 7. $2020-05-13$ \\
\hline & & 8. EPI_ISL_495291 & 8. $2020-05-13$ \\
\hline & & 9. EPI_ISL_495297 & 9. $2020-05-15$ \\
\hline 2. $\mathrm{S} 12 \mathrm{~F}$ & $1645 \mathrm{~S} 1 \mathrm{~F}(0.06 \%) 2 \mathrm{X}$ & EPI_ISL_508290 & $2020-06-21$ \\
\hline \multirow[t]{7}{*}{ 3. T22I } & \multirow[t]{7}{*}{ 1639T7I $(0.42 \%) 2 \mathrm{X}$} & 1. EPI_ISL_508169 & $1.2020-05-21$ \\
\hline & & 2.EPI_ISL_454558 & 2. $2020-04-13$ \\
\hline & & 3. EPI_ISL_479515 & 3. $2020-05-05$ \\
\hline & & 4. EPI_ISL_479516 & 4. $2020-05-05$ \\
\hline & & 5. EPI_ISL_452195 & 5. 2020-04-19 \\
\hline & & 6. EPI_ISL_452196 & 6. 2020-04-19 \\
\hline & & 7. EPI_ISL_496587 & $7.2020-05-08$ \\
\hline
\end{tabular}




\begin{tabular}{|c|c|c|c|}
\hline \multirow[t]{15}{*}{ 4. T29I } & 1630T15I $(0.91 \%) 3 \mathrm{X}$ & 1. EPI_ISL_508211 & 1. $2020-06-17$ \\
\hline & & 2. EPI_ISL_508217 & 2. $2020-06-17$ \\
\hline & & 3. EPI_ISL_508225 & 3. $2020-06-20$ \\
\hline & & 4. EPI_ISL_508228 & 4. $2020-06-20$ \\
\hline & & 5.EPI_ISL_508233 & 5. $2020-06-20$ \\
\hline & & 6. EPI_ISL_508235 & 6. $2020-06-20$ \\
\hline & & 7. EPI_ISL_508272 & 7. $2020-06-18$ \\
\hline & & 8. EPI_ISL_508273 & 8. $2020-06-18$ \\
\hline & & 9. EPI_ISL_508281 & 9. $2020-06-18$ \\
\hline & & 10. EPI_ISL_508415 & 10. $2020-06-16$ \\
\hline & & 11.EPI_ISL_508224 & 11. $2020-06-17$ \\
\hline & & 12.EPI_ISL_508263 & 12. $2020-06-18$ \\
\hline & & 13. EPI_ISL_508265 & 13. $2020-06-18$ \\
\hline & & 14. EPI_ISL_508285 & 14. $2020-06-17$ \\
\hline & & 15.EPI_ISL_495203 & 15. $2020-06-09$ \\
\hline \multirow[t]{28}{*}{ 5. L54F } & 1598L49F (3\%)1X & 1. EPI_ISL_508267 & 1. $2020-06-18$ \\
\hline & & 2. EPI_ISL_481148 & 2. $2020-05-26$ \\
\hline & & 3. EPI_ISL_512069 & 3. $2020-07-27$ \\
\hline & & 4. EPI_ISL_447046 & 4. $2020-05-04$ \\
\hline & & 5. EPI_ISL_476880 & 5. 2020-06-12 \\
\hline & & 6. EPI_ISL_447032 & 6. $2020-05-03$ \\
\hline & & 7. EPI_ISL_447033 & 7. $2020-05-03$ \\
\hline & & 8. EPI_ISL_451153 & 8. $2020-05-10$ \\
\hline & & 9. EPI_ISL_458100 & 9. $2020-05-24$ \\
\hline & & 10. EPI_ISL_458101 & 10. $2020-05-24$ \\
\hline & & 11. EPI_ISL_458112 & 11. $2020-05-18$ \\
\hline & & 12. EPI_ISL_458113 & 12. $2020-05-18$ \\
\hline & & 13. EPI_ISL_475027 & 13. $2020-06-07$ \\
\hline & & 14. EPI_ISL_475029 & 14. $2020-06-07$ \\
\hline & & 15. EPI_ISL_475030 & 15. 2020-06-11 \\
\hline & & 16. EPI_ISL_475031 & 16. $2020-06-11$ \\
\hline & & 17.EPI_ISL_475033 & 17. $2020-06-11$ \\
\hline & & 18. EPI_ISL_475034 & 18. $2020-06-11$ \\
\hline & & 19. EPI_ISL_475037 & 19. $2020-06-11$ \\
\hline & & 20. EPI_ISL_475039 & 20. $2020-06-11$ \\
\hline & & 21. EPI_ISL_475046 & 21. $2020-06-11$ \\
\hline & & 22. EPI_ISL_475047 & 22. $2020-06-05$ \\
\hline & & 23. EPI_ISL_475048 & 23. $2020-06-05$ \\
\hline & & 24. EPI_ISL_475050 & 24. $2020-06-08$ \\
\hline & & 25.EPI_ISL_475051 & 25. $2020-06-08$ \\
\hline & & 26. EPI_ISL_475052 & 26. $2020-06-08$ \\
\hline & & 27. EPI_ISL_475053 & 27. $2020-06-08$ \\
\hline & & 28. EPI_ISL_475054 & 28. $2020-06-08$ \\
\hline
\end{tabular}




\begin{tabular}{|c|c|c|c|}
\hline & & 29. EPI_ISL_475055 & 29. 2020-06-08 \\
\hline & & 30. EPI_ISL_475056 & 30. $2020-06-08$ \\
\hline & & 31. EPI_ISL_475057 & 31. 2020-06-08 \\
\hline & & 32. EPI_ISL_476855 & 32. $2020-06-08$ \\
\hline & & 33. EPI_ISL_476856 & 33. 2020-06-08 \\
\hline & & 34. EPI_ISL_476857 & 34. $2020-06-08$ \\
\hline & & 35. EPI_ISL_476858 & 35. 2020-06-08 \\
\hline & & 36. EPI_ISL_476859 & 36. $2020-06-08$ \\
\hline & & 37. EPI_ISL_476860 & 37. $2020-06-08$ \\
\hline & & 38. EPI_ISL_476861 & 38. $2020-06-08$ \\
\hline & & 39. EPI_ISL_476862 & 39. 2020-06-08 \\
\hline & & 40. EPI_ISL_476868 & 40. $2020-06-12$ \\
\hline & & 41. EPI_ISL_476870 & 41. $2020-06-11$ \\
\hline & & 42. EPI_ISL_476871 & 42. $2020-06-11$ \\
\hline & & 43. EPI_ISL_476872 & 43. 2020-06-11 \\
\hline & & 44. EPI_ISL_476873 & 44. $2020-06-11$ \\
\hline & & 45. EPI_ISL_476876 & 45. $2020-06-12$ \\
\hline & & 46. EPI_ISL_476882 & 46. $2020-06-12$ \\
\hline & & 47. EPI_ISL_495021 & 47. $2020-06-30$ \\
\hline & & 48. EPI_ISL_495022 & 48. $2020-06-30$ \\
\hline & & 49. EPI_ISL_495033 & 49. $2020-06-15$ \\
\hline \multirow[t]{15}{*}{ 6. K77M } & $1627 \mathrm{~K} 15 \mathrm{M}(0.91 \%) 6 \mathrm{X}$ & 1. EPI_ISL_436419 & 1. $2020-03-31$ \\
\hline & & 2.EPI_ISL_486389 & 2. $2020-05-10$ \\
\hline & & 3.EPI_ISL_486408 & 3. $2020-05-10$ \\
\hline & & 4. EPI_ISL_486409 & 4. $2020-05-10$ \\
\hline & & 5.EPI_ISL_481127 & 5. $2020-05-22$ \\
\hline & & 6. EPI_ISL_436450 & 6. 2020-04-13 \\
\hline & & 7. EPI_ISL_447571 & 7. $2020-04-01$ \\
\hline & & 8. EPI_ISL_447556 & 8. $2020-03-30$ \\
\hline & & 9. EPI_ISL_447566 & 9. 2020-04-01 \\
\hline & & 10. EPI_ISL_447850 & 10. 2020-04-01 \\
\hline & & 11. EPI_ISL_447856 & 11. 2020-04-02 \\
\hline & & 12. EPI_ISL_447858 & 12. $2020-04-06$ \\
\hline & & 13. EPI_ISL_450330 & 13. 2020-04-02 \\
\hline & & 14. EPI_ISL_458072 & 14. $2020-04-08$ \\
\hline & & 15. EPI_ISL_471585 & 15. $2020-04-08$ \\
\hline \multirow[t]{5}{*}{ 7. $\mathrm{R} 78 \mathrm{M}$} & 1643R5M (0.30\%) & 1.EPI_ISL_512075 & 1. 2020-07-09 \\
\hline & & 2. EPI_ISL_512077 & 2. 2020-07-09 \\
\hline & & 3.EPI_ISL_514435 & 3. 2020-07-09 \\
\hline & & 4. EPI_ISL_514436 & 4. 2020-07-09 \\
\hline & & 5.EPI_ISL_514437 & 5. 2020-07-09 \\
\hline \multirow[t]{3}{*}{ 8. D80Y } & 1645D3Y (0.18\%) & 1.EPI_ISL_481163 & 1. 2020-06-04 \\
\hline & & 2.EPI_ISL_481164 & 2. $2020-06-04$ \\
\hline & & 3. EPI_ISL_481165 & 3. 2020-06-04 \\
\hline
\end{tabular}




\begin{tabular}{|c|c|c|c|}
\hline 9. D88H & $1643 \mathrm{D} 1 \mathrm{H}(0.06 \%) 4 \mathrm{X}$ & EPI_ISL_486409 & $2020-05-10$ \\
\hline 10. E96D & 1645E1D $(0.06 \%) 2 \mathrm{X}$ & EPI_ISL_486836 & 2020 \\
\hline 11. S98F & $1647 \mathrm{~S} 1 \mathrm{~F}(0.06 \%)$ & EPI_ISL_477208 & 2020-06-01 \\
\hline \multirow[t]{9}{*}{ 12. D138Y } & 1639D9Y $(0.55 \%)$ & 1.EPI_ISL_477233 & 1. $2020-06-16$ \\
\hline & & 2.EPI_ISL_508200 & 2. 2020-06-09 \\
\hline & & 3. EPI_ISL_508231 & 3. $2020-06-20$ \\
\hline & & 4. EPI_ISL_508269 & 4. $2020-06-18$ \\
\hline & & 5. EPI_ISL_508270 & 5. $2020-06-18$ \\
\hline & & 6. EPI_ISL_508271 & 6. $2020-06-18$ \\
\hline & & 7. EPI_ISL_482641 & 7. $2020-05-27$ \\
\hline & & 8. EPI_ISL_479554 & 8. $2020-06-15$ \\
\hline & & 9. EPI_ISL_508224 & 9. $2020-06-17$ \\
\hline 13. D178N & $1646 \mathrm{D} 1 \mathrm{~N}(0.06 \%) 1 \mathrm{X}$ & EPI_ISL_477239 & 2020-06-17 \\
\hline \multirow[t]{4}{*}{ 14. G181A } & 1643G4A (0.24\%)1X & 1.EPI_ISL_508211 & 1. $2020-06-17$ \\
\hline & & 2. EPI_ISL_508263 & 2. $2020-06-18$ \\
\hline & & 3. EPI_ISL_508265 & 3. $2020-06-18$ \\
\hline & & 4. EPI_ISL_508285 & 4. $2020-06-17$ \\
\hline \multirow[t]{9}{*}{ 15. V213A } & 1638V9A $(0.55 \%) 1 \mathrm{X}$ & 1.EPI_ISL_471590 & 1. $2020-05-25$ \\
\hline & & 2.EPI_ISL_471591 & 2. $2020-05-25$ \\
\hline & & 3.EPI_ISL_471592 & 3. $2020-05-25$ \\
\hline & & 4. EPI_ISL_471593 & 4. $2020-05-25$ \\
\hline & & 5. EPI_ISL_471596 & 5. $2020-05-25$ \\
\hline & & 6. EPI_ISL_471605 & 6. $2020-05-25$ \\
\hline & & 7. EPI_ISL_471606 & 7. $2020-05-25$ \\
\hline & & 8. EPI_ISL_471607 & 8. $2020-05-25$ \\
\hline & & 9. EPI_ISL_471611 & 9. $2020-05-25$ \\
\hline \multirow[t]{4}{*}{ 16. A243S } & $1642 \mathrm{~A} 4 \mathrm{~S}(0.24 \%) 1 \mathrm{~V}(0.06 \%) 1 \mathrm{X}$ & 1. EPI_ISL_436449(S) & 1. $2020-04-12$ \\
\hline & & 2. EPI_ISL_496569(S) & 2. $2020-05-21$ \\
\hline & & 3. EPI_ISL_496535 (S) & 3. $2020-05-21$ \\
\hline & & 4. EPI_ISL_436426(S) & 4. $2020-04-05$ \\
\hline A243V & & EPI_ISL_477262(V) & $2020-05-20$ \\
\hline \multirow[t]{2}{*}{ 17. G261S } & $1643 \mathrm{G} 2 \mathrm{~S}(0.12 \%) 3 \mathrm{X}$ & 1. EPI_ISL_455666 & 1. $2020-05-01$ \\
\hline & & 2.EPI_ISL_463070 & 2. $2020-05-14$ \\
\hline 18. T274I & 1644T1I $(0.06 \%) 3 \mathrm{X}$ & EPI_ISL_436416 & $2020-03-31$ \\
\hline 19. T286I & 1646T1I $(0.06 \%) 1 \mathrm{X}$ & EPI_ISL_508182 & 2020-06-08 \\
\hline \multirow[t]{2}{*}{ 20. T323I } & 1644T2I $(0.12 \%) 2 \mathrm{X}$ & 1. EPI_ISL_455655 & 1. $2020-04-30$ \\
\hline & & 2. EPI_ISL_455663 & 2. $2020-05-02$ \\
\hline 21. A344S & 1647A1S $(0.06 \%)$ & EPI_ISL_477247 & 2020 \\
\hline \multirow[t]{2}{*}{ 22. V367F } & $1646 \mathrm{~V} 2 \mathrm{~F}(0.12 \%)$ & 1.EPI_ISL_463064 & 1. $2020-05-16$ \\
\hline & & 2.EPI_ISL_463065 & 2. $2020-05-14$ \\
\hline 23. I402L & 1647I1L (0.06\%) & EPI_ISL_455773 & 2020-04-04 \\
\hline 24. R408I & 1645R1I $(0.06 \%) 2 \mathrm{X}$ & EPI_ISL_413522 & $2020-01-27$ \\
\hline 25. $\mathrm{T} 470 \mathrm{~N}$ & $1647 \mathrm{~T} 1 \mathrm{~N}(0.06 \%)$ & EPI_ISL_482563 & 2020-05-19 \\
\hline
\end{tabular}




\begin{tabular}{|c|c|c|c|}
\hline 26. E471D & $\begin{array}{l}\text { 1646E1D }(0.06 \%) \\
1 Q(0.06 \%)\end{array}$ & $\begin{array}{l}\text { EPI_ISL_508226(D) } \\
\text { EPI_ISL_447046(Q) }\end{array}$ & $\begin{array}{l}2020-06-20 \\
2020-05-04\end{array}$ \\
\hline \multicolumn{4}{|l|}{ E471Q } \\
\hline 27. G476S & 1647G1S (0.06\%) & EPI_ISL_479493 & 2020-04-15 \\
\hline 28. N481D & $1646 \mathrm{~N} 1 \mathrm{D}(0.06 \%) 1 \mathrm{X}$ & EPI_ISL_477238 & $2020-06-16$ \\
\hline \multirow[t]{3}{*}{ 29. G482S } & $1644 G 3 S(0.18 \%) 1 X$ & 1. EPI_ISL_495222 & 1. $2020-06-11$ \\
\hline & & 2. EPI_ISL_495273 & 2. $2020-06-13$ \\
\hline & & 3. EPI_ISL_495264 & 3. $2020-06-13$ \\
\hline \multirow[t]{3}{*}{ 30. E484Q } & 1645E3Q (0.18\%) & 1. EPI_ISL_454530 & 1. $2020-03-22$ \\
\hline & & 2. EPI_ISL_495014 & 2. $2020-06-18$ \\
\hline & & 3. EPI_ISL_495015 & 3. $2020-06-18$ \\
\hline 31. S494P & $1647 \mathrm{~S} 1 \mathrm{P}(0.06 \%)$ & EPI_ISL_436419 & $2020-03-31$ \\
\hline \multirow[t]{8}{*}{ 32. A520S } & 1627A8S $(0.49 \%) 13 \mathrm{X}$ & 1. EPI_ISL_458045 & 1. $2020-05-11$ \\
\hline & & 2. EPI_ISL_458046 & 2. $2020-05-11$ \\
\hline & & 3. EPI_ISL_458047 & 3. $2020-05-11$ \\
\hline & & 4. EPI_ISL_458048 & 4. $2020-05-11$ \\
\hline & & 5. EPI_ISL_458049 & 5. $2020-05-11$ \\
\hline & & 6. EPI_ISL_458050 & 6. $2020-05-11$ \\
\hline & & 7. EPI_ISL_495161 & 7. $2020-05-11$ \\
\hline & & 8. EPI_ISL_495162 & 8. $2020-05-11$ \\
\hline 33. E554Q & 1647E1Q (0.06\%) & EPI_ISL_508156 & 2020-06-01 \\
\hline \multirow[t]{2}{*}{ 34. K558N } & $1645 \mathrm{~K} 2 \mathrm{~N}(0.12 \%) 1 \mathrm{X}$ & 1. EPI_ISL_458035 & 1. $2020-04-29$ \\
\hline & & 2. EPI_ISL_452210 & 2. $2020-04-06$ \\
\hline 35. F565L & 1647F1L (0.06\%) & EPI_ISL_508320 & 2020-06-04 \\
\hline \multirow[t]{5}{*}{ 36. T572I } & 1642T5I $(0.30 \%) 1 \mathrm{X}$ & 1. EPI_ISL_458103 & 1. $2020-05-05$ \\
\hline & & 2.EPI_ISL_447035 & 2. $2020-05-03$ \\
\hline & & 3. EPI_ISL_458090 & 3. $2020-05-24$ \\
\hline & & 4. EPI_ISL_458091 & 4. $2020-05-24$ \\
\hline & & 5. EPI_ISL_461484 & 5. $2020-05-27$ \\
\hline \multirow[t]{8}{*}{ 37. E583D } & 1639E8D $(0.49 \%) 1 \mathrm{X}$ & 1. EPI_ISL_476854 & 1. $2020-05-11$ \\
\hline & & 2.EPI_ISL_496576 & 2. $2020-05-21$ \\
\hline & & 3. EPI_ISL_512066 & 3. $2020-07-27$ \\
\hline & & 4. EPI_ISL_461485 & 4. $2020-05-27$ \\
\hline & & 5. EPI_ISL_461495 & 5. $2020-05-27$ \\
\hline & & 6. EPI_ISL_495271 & 6. $2020-06-13$ \\
\hline & & 7. EPI_ISL_467050 & 7. $2020-06-03$ \\
\hline & & 8. EPI_ISL_469028 & 8. $2020-06-03$ \\
\hline \multirow[t]{3}{*}{ 38. D614G } & 499D (30.3\%) & Many & Many \\
\hline & $1122 \mathrm{G}(68.1 \%)$ & & \\
\hline & $27 X(1.64 \%)$ & & \\
\hline \multirow[t]{4}{*}{ 39. $\mathrm{V} 622 \mathrm{~F}$} & $1642 \mathrm{~V} 6 \mathrm{~F}(0.36 \%)$ & 1. EPI_ISL_481163 & 1. $2020-06-04$ \\
\hline & & 2. EPI_ISL_481164 & 2. $2020-06-04$ \\
\hline & & 3. EPI_ISL_481165 & 3. 2020-06-04 \\
\hline & & 4. EPI ISL 481166 & 4. $2020-06-04$ \\
\hline
\end{tabular}




\begin{tabular}{|c|c|c|c|}
\hline & & 5. EPI_ISL_495195 & 5. 2020-06-08 \\
\hline & & 6. EPI_ISL_495239 & 6. $2020-06-12$ \\
\hline 40. $\mathrm{A653V}$ & 1646A1X1V (0.06\%) & EPI_ISL_486837 & 2020 \\
\hline 41. $A 672 \mathrm{~V}$ & 1647A1V (0.06\%) & EPI_ISL_508203 & 2020-06-08 \\
\hline \multirow[t]{2}{*}{ 42. Q675R } & 1642Q1R (0.06\%)5H (0.30\%) & EPI_ISL_508181(R) & 2020-06-02 \\
\hline & & 1. EPI_ISL_508231 (H) & 1. $2020-06-20$ \\
\hline \multirow[t]{4}{*}{ Q675H } & & 2. EPI_ISL_508269 (H) & 2. $2020-06-18$ \\
\hline & & 3. EPI_ISL_508270 (H) & 3. $2020-06-18$ \\
\hline & & 4. EPI_ISL_508271 (H) & 4. $2020-06-18$ \\
\hline & & 5. EPI_ISL_476864 (H) & 5. $2020-06-11$ \\
\hline \multirow[t]{12}{*}{ 43. Q677H } & 1632Q12H $(0.73 \%) 2 \mathrm{R}(0.12 \%) 2 \mathrm{X}$ & 1. EPI_ISL_477216 (H) & 1. $2020-06-09$ \\
\hline & & 2. EPI_ISL_508336(H) & 2. $2020-06-20$ \\
\hline & & 3. EPI_ISL_508419(H) & 3. $2020-06-27$ \\
\hline & & 4. EPI_ISL_452215 (H) & 4. $2020-04-22$ \\
\hline & & 5. EPI_ISL_454550 (H) & 5. 2020-04-06 \\
\hline & & 6. EPI_ISL_452210 (H) & 6. 2020-04-06 \\
\hline & & 7. EPI_ISL_452197 (H) & 7. $2020-04-19$ \\
\hline & & 8. EPI_ISL_508420 (H) & 8. $2020-06-18$ \\
\hline & & 9. EPI_ISL_508263 (H) & 9. $2020-06-18$ \\
\hline & & 10. EPI_ISL_508265 (H) & 10. $2020-06-18$ \\
\hline & & 11. EPI_ISL_508285 (H) & 11. 2020-06-17 \\
\hline & & 12. EPI_ISL_476875 (H) & 12. $2020-06-12$ \\
\hline \multirow[t]{2}{*}{ Q677R } & & 1. EPI_ISL_508189 (R) & 13. $2020-05-23$ \\
\hline & & 2. EPI_ISL_508190 (R) & 14. $2020-05-23$ \\
\hline 44. N679T & $1647 \mathrm{~N} 1 \mathrm{~T}(0.06 \%)$ & EPI_ISL_508181 & 2020-06-02 \\
\hline 45. S698L & $1647 \mathrm{~S} 1 \mathrm{~L}(0.06 \%)$ & EPI_ISL_508169 & $2020-05-21$ \\
\hline 46. T723I & 1647T1I (0.06\%) & EPI_ISL_430466 & $2020-03-26$ \\
\hline \multirow[t]{2}{*}{ 47. $\mathrm{R} 765 \mathrm{~L}$} & 1646R2L $(0.12 \%)$ & 1. EPI_ISL_477240 & 1. $2020-06-17$ \\
\hline & & 2. EPI_ISL_479744 & 2. $2020-06-17$ \\
\hline \multirow[t]{4}{*}{ 48. P812L } & 1634P4L (0.24\%)10X & 1. EPI_ISL_508198 & 1. $2020-06-09$ \\
\hline & & 2. EPI_ISL_512068 & 2. $2020-07-27$ \\
\hline & & 3. EPI_ISL_512067 & 3. $2020-07-27$ \\
\hline & & 4. EPI_ISL_512076 & 4. $2020-07-09$ \\
\hline \multirow[t]{3}{*}{ 49. D839Y } & 1645D3Y $(0.18 \%)$ & 1. EPI_ISL_477222 & 1. $2020-06-11$ \\
\hline & & 2. EPI_ISL_486838 & 2. 2020 \\
\hline & & 3. EPI_ISL_508428 & 3. $2020-05-17$ \\
\hline 50. A852T & 1647A1T (0.06\%) & EPI_ISL_508198 & 2020-06-09 \\
\hline 51. L858F & 1647L1F $(0.06 \%)$ & EPI_ISL_508297 & $2020-06-17$ \\
\hline 52. S884F & $1647 \mathrm{~S} 1 \mathrm{~F}(0.06 \%)$ & EPI_ISL_476894 & $2020-05-18$ \\
\hline 53. S929 & $1646 \mathrm{~S}$ & EPI_ISL_476883(T) & $2020-05-1320$ \\
\hline \multirow[t]{2}{*}{ TS929I } & $1 \mathrm{~T}(0.06 \%)$ & & \\
\hline & 1I $(0.06 \%)$ & EPI_ISL_508234(I) & $20-06-17$ \\
\hline 54. A930V & $\begin{array}{l}\text { 1646A1V }(0.06 \%) \\
1 \mathrm{~T}(0.06 \%)\end{array}$ & $\begin{array}{l}\text { EPI_ISL_413523(V) } \\
\text { EPI_ISL_455761 (T) }\end{array}$ & $\begin{array}{l}2020-01-31 \\
2020-05-07\end{array}$ \\
\hline A930T & & & \\
\hline
\end{tabular}




\begin{tabular}{|c|c|c|c|}
\hline 55. T941K & $1647 \mathrm{~T} 1 \mathrm{~K}(0.06 \%)$ & EPI_ISL_455640 & $2020-03-27$ \\
\hline 56. S967G & $1647 \mathrm{~S} 1 \mathrm{G}(0.06 \%)$ & EPI_ISL_477243 & $2020-06-16$ \\
\hline 57. L981P & 1647L1P (0.06\%) & EPI_ISL_508332 & $2020-05-27$ \\
\hline 58. T1027I & 1647T1I (0.06\%) & EPI_ISL_454831 & 2020-04-29 \\
\hline 59. S1030L & 1647S1L $(0.06 \%)$ & EPI_ISL_486667 & 2020 \\
\hline 60. K1045N & $1646 \mathrm{~K} 1 \mathrm{~N}(0.06 \%) 1 \mathrm{X}$ & EPI_ISL_508330 & 2020-06-03 \\
\hline \multirow[t]{7}{*}{ 61. A1078S } & $1640 \mathrm{~A} 7 \mathrm{~S}(0.42 \%) 1 \mathrm{X}$ & 1. EPI_ISL_496526 & 1. $2020-05-21$ \\
\hline & & 2. EPI_ISL_496531 & 2. $2020-05-21$ \\
\hline & & 3. EPI_ISL_496532 & 3. $2020-05-22$ \\
\hline & & 4. EPI_ISL_496573 & 4. $2020-05-21$ \\
\hline & & 5. EPI_ISL_496574 & 5. $2020-05-21$ \\
\hline & & 6. EPI_ISL_496575 & 6. $2020-05-21$ \\
\hline & & 7. EPI_ISL_496577 & 7. $2020-05-22$ \\
\hline \multirow[t]{3}{*}{ 62. D1084Y } & 1645D3Y (0.18\%) & 1.EPI_ISL_486389 & 1. $2020-05-10$ \\
\hline & & 2. EPI_ISL_486408 & 2. $2020-05-10$ \\
\hline & & 3.EPI_ISL_486409 & 3. $2020-05-10$ \\
\hline \multirow[t]{2}{*}{ 63. P1162S } & $1647 \mathrm{P}$ & EPI_ISL_477261 & \\
\hline & $1 \mathrm{~S}(0.06 \%)$ & & \\
\hline \multirow[t]{3}{*}{ 64. I1179V } & $1645 \mathrm{I}$ & EPI_ISL_486836 & 2020 \\
\hline & $1 \mathrm{~V}(0.06 \%)$ & & \\
\hline & $2 \mathrm{~N}(0.12 \%)$ & 1. EPI_ISL_454563 & 1. $2020-04-10$ \\
\hline I1179N & & 2. EPI_ISL_454528 & 2. $2020-03-17$ \\
\hline \multirow[t]{4}{*}{ 65. C1243F } & $1644 \mathrm{C} 4 \mathrm{~F}(0.24 \%)$ & 1. EPI_ISL_452792 & 1. $2020-04-30$ \\
\hline & & 2.EPI_ISL_481199 & 2. $2020-06-10$ \\
\hline & & 3. EPI_ISL_437445 & 3. $2020-04-26$ \\
\hline & & 4. EPI_ISL_437446 & 4. $2020-04-26$ \\
\hline 66. $\mathrm{C} 1250 \mathrm{~F}$ & $1646 \mathrm{C} 1 \mathrm{~F}(0.06 \%) 1 \mathrm{X}$ & EPI_ISL_428482 & 2020-04-08 \\
\hline
\end{tabular}

crystal structure used, amino acids of SARS-CoV2 RBD region observed to be interacting with ACE2 receptor were A475, Y489, F486, N487, E484, Y453, K417, Y449, G496, Q498, G446, G502 and T500. Mutation site 484 with respect to the E484Q mutation in the Indian isolates and other mutations localize around the ACE2 interacting amino acids. This implies possible effect of these mutations on receptor attachment.

\section{Landscape of Spike Protein Mutations in Indian Patients}

To correlate our basic overall understanding of the mutation hot-spots in the spike protein from other parts of the world with Indian variations, we tried to study almost all available translatable good quality sequences with respect to the spike protein from the GISAID database. Such sequences represented multiple Indian states and widely distributed sample collection time points. Multiple new mutations were detected in the spike glycoprotein sequence of the Indian isolates that were not detected in other countries (Table 7, Figs. 2B-C). One particular mutation V367F lying in the RBD region of the protein was initially detected in a Chinese isolate in the month of January (Table 6) and our analysis detected this mutation only in Indian isolates collected in the month of May, 2020 with a frequency of $0.12 \%$. This mutation was not detected in any other countries as per sequences analysed thus suggesting either minor independent mutation that might have emerged in India after the outbreak. Since the international flights were restricted inflow of infected individuals carrying this mutation from China 
is less likely. Since the percentage of individuals having this mutation was less and that the mutation emerged in the month of May, not detected in later months, it might not have spread very efficiently as of sequence information available currently. However, since the mutation lies in the RBD region, monitoring possible future expansion and selection of such mutations might add on to the therapeutics field where RBD is been targeted.

The major mutations that were detected in the RBD region of the spike protein in other countries were not detected in the Indian isolates except G476S. Rather, multiple independent new mutations emerged in the spike protein of Indian SARS-CoV-2 isolates as highlighted in Table 7 . The new mutations which appeared in the samples collected in the months of June and July, 2020,were distributed in both the S1 and S2 domains out of which some were also from the $\mathrm{RBD}$ region of the protein.

Recent studies have identified two protease cleavage sites in the Spike glycoprotein, S1/S2 cleavage site (681st-684th) and S2' cleavage site (811th-815th). These two sites have been shown to be important for the proteolytic processing of the protein which increases its efficiency to interact with

\section{References}

Bestle et al. (2020) TMPRSS2 and furin are both essential for proteolytic activation and spread of SARS2 CoV-2 in human airway epithelial cells and provide promising drug targets. https://doi.org/10.1101/2020.04.15.042085

Feng X, Wang Z, Shi J, Deng G, Kong H et al. (2016) Glycine at Position 622 in PB1 Contributes to the Virulence of H5N1 Avian Influenza Virus in Mice Journal of Virology 90 18721879

Hoffmann M, Kleine-Weber H, Pöhlmann S (2020) A Multibasic Cleavage Site in the Spike Protein of SARS-CoV-2 Is Essential for Infection of Human Lung Cells Mol Cell 78 779-784.e5. doi:10.1016/j.molcel.2020.04.022

Hoffmann M, Kleine-Weber H, Schroeder S, et al. (2020) SARSCoV-2 Cell Entry Depends on ACE2 and TMPRSS2 and the host cell receptors and mediate cellular transduction process (Hoffman et al. 2020; Walls et al. 2020; Bestle et al. 2020). Our mutational analysis reveals multiple mutations near the $\mathrm{S} 1 / \mathrm{S} 2$ cleavage site (A672V, Q675R, Q675H, Q677H, Q677R, N679T, S698L) and one in the S2' cleavage site (P812L) that emerged recently in the Indian isolates. These mutations might influence the efficacy of activity of the enzymes with respect to the cleavage sites although this hypothesis is subject to experimental validations. Nonetheless, considering importance of these proteolytic cleavage events in the virus entry process, mutations might alter the tropism and transduction mechanism if such mutations succeed to get selected in the virus evolutionary process.

The data presented here is based on the currently analyzed sequences. Further sequencing and mutation analyses would shed more light on the nature of this virus and might alternatively influence the mutational profile and inference drawn.

\section{Acknowledgements}

CSIR is acknowledged for research support and fellowship to FB. North Bengal Medical College and Hospital is also deeply acknowledged. We thank AcSIR for academic support.

Is Blocked by a Clinically Proven Protease Inhibitor Cell 181 271-280.e8. doi:10.1016/j.cell.2020.02.052

Lan J, Ge J, Yu J, et al. Structure of the SARS-CoV-2 spike receptor-binding domain bound to the ACE2 receptor Nature 2020581 215-220 doi: 10.1038/s41586-020-21805

Tai W, He L, Zhang X, Pu J, Voronin D, Jiang S et al. Characterization of the receptor-binding domain (RBD) of (2019) novel coronavirus: Implication for development of RBD protein as a viral attachment inhibitor and vaccine. 2020

Walls A C, Park Y J, Tortorici M A, Wall A, McGuire A T, Veesler D (2020) Structure, Function, and Antigenicity of the SARS-CoV-2 Spike Glycoprotein Cell 181 281292.e6. doi:10.1016/j.cell.2020.02.058. 